\title{
Cannabinoids as Pharmacotherapies for Neuropathic Pain: From the Bench to the Bedside
}

\author{
Elizabeth J. Rahn and Andrea G. Hohmann \\ Neuroscience and Behavior Program, Department of Psychology, University of Georgia, Athens, Georgia 30602
}

\begin{abstract}
Summary: Neuropathic pain is a debilitating form of chronic pain resulting from nerve injury, disease states, or toxic insults. Neuropathic pain is often refractory to conventional pharmacotherapies, necessitating validation of novel analgesics. Cannabinoids, drugs that share the same target as $\Delta^{9}$-tetrahydrocannabinol ( $\Delta^{9}$-THC), the psychoactive ingredient in cannabis, have the potential to address this unmet need. Here, we review studies evaluating cannabinoids for neuropathic pain management in the clinical and preclinical literature. Neuropathic pain associated with nerve injury, diabetes, chemotherapeutic treatment, human immunodeficiency virus, multiple sclerosis, and herpes zoster infection is considered. In animals, cannabinoids attenuate neuropathic nociception produced by traumatic nerve injury, disease, and toxic insults. Effects of mixed cannabinoid $\mathrm{CB}_{1} / \mathrm{CB}_{2}$ agonists, $\mathrm{CB}_{2}$ selective agonists, and modulators of the endocannabinoid system (i.e., inhibitors of transport or
\end{abstract}

degradation) are compared. Effects of genetic disruption of cannabinoid receptors or enzymes controlling endocannabinoid degradation on neuropathic nociception are described. Specific forms of allodynia and hyperalgesia modulated by cannabinoids are also considered. In humans, effects of smoked marijuana, synthetic $\Delta^{9}$-THC analogs (e.g., Marinol, Cesamet) and medicinal cannabis preparations containing both $\Delta^{9}$-THC and cannabidiol (e.g., Sativex, Cannador) in neuropathic pain states are reviewed. Clinical studies largely affirm that neuropathic pain patients derive benefits from cannabinoid treatment. Subjective (i.e., rating scales) and objective (i.e., stimulusevoked) measures of pain and quality of life are considered. Finally, limitations of cannabinoid pharmacotherapies are discussed together with directions for future research. Key Words: Endocannabinoid, marijuana, neuropathy, multiple sclerosis, chemotherapy, diabetes.

\section{NEUROPATHIC PAIN}

Neuropathic pain is a debilitating form of treatmentresistant chronic pain caused by damage to the nervous system. Neuropathic pain may result from peripheral nerve injury, toxic insults, and disease states. Neuropathic pain remains a significant clinical problem because it responds poorly to available therapies. Moreover, adverse side effect profiles may limit therapeutic dosing and contribute to inadequate pain relief. Drug discovery efforts have consequently been directed toward identifying novel analgesic targets for drug development. This review will evaluate the efficacy of cannabinoids as analgesics for the treatment of neuropathic pain from the bench to the bedside.

Address correspondence and reprint requests to: Andrea G. Hohmann, Neuroscience and Behavior Program, Department of Psychology, University of Georgia, Athens, GA 30602-3013. E-mail: ahohmann@ uga.edu.

\section{CANNABINOID RECEPTOR PHARMACOLOGY}

Evidence for the use of Cannabis sativa as a treatment for pain can be traced back to the beginnings of recorded history. The discovery by Gaoni and Mechoulam ${ }^{1}$ of $\Delta^{9}$ tetrahydrocannabinol $\left(\Delta^{9}-\mathrm{THC}\right)$, the primary psychoactive ingredient in cannabis, set the stage for the identification of an endogenous cannabinoid (endocannabinoid) transmitter system in the brain. The endocannabinoid signaling system includes cannabinoid receptors (e.g., $\mathrm{CB}_{1}$ and $\mathrm{CB}_{2}$ ), their endogenous ligands (e.g., anandamide and 2-arachidonoylglycerol), and the synthetic and hydrolytic enzymes that control the bioavailability of the endocannabinoids. Both $\mathrm{CB}_{1}{ }^{2}$ and $\mathrm{CB}_{2}{ }^{3}$ receptors are G-coupled protein receptors that are negatively coupled to adenylate cyclase. Activation of $\mathrm{CB}_{1}$ receptors suppresses calcium conductance and inhibits inward rectifying potassium conductance, thereby suppressing neuronal excitability and transmitter release. $\mathrm{CB}_{2}$ receptor activation stimulates MAPK activity but does not modulate calcium or potassium conductances. ${ }^{4}$ The development of $\mathrm{CB}_{1}{ }^{5}$ and $\mathrm{CB}_{2}{ }^{6}$ receptor knockout mice has helped elucidate the 
physiological roles of cannabinoid receptors in the nervous system. Generation of $\mathrm{CB}_{1}^{-1-}$ mice that lack $\mathrm{CB}_{1}$ receptors in nociceptive neurons in the peripheral nervous system while retaining CNS expression (SNS$\mathrm{CB}_{1}^{-}$) has also documented a role for these receptors in controlling nociception. ${ }^{7}$

$\mathrm{CB}_{1}$ and $\mathrm{CB}_{2}$ receptors exhibit disparate anatomical distributions. ${ }^{3} \mathrm{CB}_{1}$ receptors are localized to the $\mathrm{CNS}$ and the periphery. $\mathrm{CB}_{1}$ receptors are found in sites associated with pain processing, including the periaqueductal gray, ${ }^{8}$ rostral ventromedial medulla, ${ }^{8}$ thalamus, ${ }^{9}$ dorsal root ganglia (DRG), ${ }^{10}$ amygdala, ${ }^{8}$ and cortex. ${ }^{8}$ Densities of $\mathrm{CB}_{1}$ receptors are low in brainstem sites critical for controlling heart rate and respiration. This distribution explains the low toxicity and absence of lethality after marijuana intoxication. Activation of the $\mathrm{CB}_{1}$ receptor also results in hypothermia, sedation, catalepsy, and altered mental status. ${ }^{11}$ Thus, it is critical for any cannabinoid-based pharmacotherapy targeting $\mathrm{CB}_{1}$ receptors to balance clinically relevant therapeutic effects with unwanted side effects. The $\mathrm{CB}_{2}$ receptor was originally believed to be restricted to the periphery, primarily to immune cells (e.g., mast cells). ${ }^{12}$ They may be present neuronally in some species. The $\mathrm{CB}_{2}$ receptor protein has been reported in the DRG, ${ }^{13}$ brainstem, ${ }^{14}$ thalamus, ${ }^{15}$ periaqueductal gray, ${ }^{15}$ and cerebellum ${ }^{15,16}$ of naive rats. $\mathrm{CB}_{2}$ receptor levels in most $\mathrm{CNS}$ sites are present at only low levels under basal conditions (or are below the threshold for detection). However, an upregulation of $\mathrm{CB}_{2}$ receptor immunoreactivity or mRNA is observed in sites implicated in nociceptive processing under conditions of induced neuropathy. ${ }^{17,18} \mathrm{CB}_{2}$ receptors are localized to microglia, a resident population of macrophages within the CNS that are functionally and anatomically similar to mast cells. Microglia secrete proinflammatory factors and induce the release of several mediators (e.g., nitric oxide, neurotrophins, free radicals) that are associated with synaptogenesis and plasticity, leading to changes in neuronal excitability.

\section{ENDOCANNABINOIDS}

The first endogenous ligand for cannabinoid receptors $^{19}$ was named anandamide (AEA) after the sankrit word for bliss. Several other endocannabinoids including 2-arachydonoylglycerol (2-AG), ${ }^{20,21}$ noladin ether, ${ }^{22}$ virodhamine, ${ }^{23}$ and $\mathrm{N}$-arachidonoly-dopamine ${ }^{24}$ have been described. Fatty-acid amide hydrolase (FAAH) is the principle catabolic enzyme for fatty-acid amides including AEA and $N$-palmitoylethanolamine (PEA). ${ }^{25}$ PEA does not bind cannabinoid receptors and has recently been described as an endogenous ligand for peroxisome proliferator receptor- $\alpha$ (PPAR- $\alpha$ ) ${ }^{26}$ PEA may indirectly alter levels of endocannabinoids by competing with anandamide and other fatty-acid amides for degradation by FAAH or by suppressing FAAH expression at the transcriptional level. ${ }^{27,28} \mathrm{FAAH}^{-1-}$ mice are hypoalgesic in models of acute and inflammatory pain; these effects are blocked by a $\mathrm{CB}_{1}$ antagonist. ${ }^{29,30}$ This basal hypoalgesia is absent in $\mathrm{FAAH}^{-1-}$ mice subjected to nerve injury, where genotype differences in evoked neuropathic pain behaviors are not apparent. ${ }^{30}$

Anandamide also acts as an endovanalloid at the transient receptor potential cation channel (TRPV1) receptor. ${ }^{31}$ AEA shows affinity for TRPV1 that is 5- to 20 -fold lower than its affinity for $\mathrm{CB}_{1}$. TRPV1 is not activated by classical, nonclassical, or aminoalkylindole cannabinoid agonists. AEA can also activate the peroxisome proliferator receptor- $\gamma(\operatorname{PPAR} \gamma)$ receptor. ${ }^{32}$ Thus, not all effects of AEA are mediated by cannabinoid receptors.

The metabolic pathways responsible for endocannabinoid degradation are well-characterized. Several FAAH inhibitors (e.g., OL135, URB597) have been developed and used to investigate physiological effects of increasing accumulation of AEA and other fatty-acid amides. Monoacylglycerol lipase (MGL) is a key enzyme implicated in the hydrolysis of $2-\mathrm{AG}^{33,34} \mathrm{MGL}$ inhibitors (e.g., URB602, JZL184) have been developed and can be used to selectively increase accumulation of this endocannabinoid. The endocannabinoid system has complex relationships with other metabolic pathways. Both AEA and 2-AG can be metabolized by cyclooxygenase- 2 , a phenomenon that may contribute to the antinociceptive properties of nonsteroidal antiinflammatory drugs that act through inhibition of cyclooxygenase-2. ${ }^{4}$ Table 1 provides a summary of cannabinoids and related compounds that have been evaluated for efficacy in preclinical and clinical studies of neuropathic pain.

\section{CANNABINOID MODULATION OF NEUROPATHIC NOCICEPTION IN ANIMAL MODELS}

W. E. Dixon ${ }^{35}$ was the first scientist to systematically study the antinociceptive properties of Cannabis sativa. Dixon $^{35}$ reported that cannabis smoke delivered to dogs attenuated their responsiveness to pin pricks. He observed that normally "evil-tempered and savage" dogs became "docile and affectionate" after exposure to cannabis, reflecting the psychotropic and mood-altering effects of cannabinoids. Motor effects observed after high doses of cannabinoids included drowsiness, awkward gate, and ataxia. Work by Walker's group subsequently demonstrated that cannabinoids suppress nociceptive transmission (for review see ${ }^{36}$ ). Early observations of the antinociceptive properties of cannabinoids laid a foundation for future research examining the impact of canna- 
Table 1. Cannabinoids Evaluated for Suppression of Neuropathic Nociception

Natural cannabinoid ligands and synthetic analogues

- $\Delta^{9}$-THC (Dronabinol/Marinol)

- Cannabidiol (CBD)

- Cannador (cannabis extract, $\Delta^{9}$-THC:CBD, $2.5 \mathrm{mg}: 1.25 \mathrm{mg}$ )

- Cannabis

- eCBD (Cannabis with high CBD content)

- Nabilone (Cesamet, $\Delta^{9}$-THC analogue)

- Sativex (oral-mucosal spray, $\Delta^{9}$-THC:CBD, $2.7 \mathrm{mg}: 2.5 \mathrm{mg}$ )

Endocannabinoids

- Anandamide (AEA)

- 2-arachydonoylglycerol (2-AG)

Fatty acids

- L-29

- N-arachidonoyl glycine (NaGly)

- Palmitoylethanolamine (PEA)

$\mathrm{CB}_{1}$-selective agonists

- ACEA

- Met-F-AEA

Mixed $\mathrm{CB}_{1} / \mathrm{CB}_{2}$ agonists

- BAY59-3074

- CP55,940

- CT-3 (Ajulemic acid)

- HU-210

- WIN55,212-2

$\mathrm{CB}_{2}$-selective agonists

- A-796260

- A-836339

- AM1241 ((R,S)-AM1241)

- (R)-AM1241

- (S)-AM1241

- AM1714

- Compound 27

- GW405833 (L768242)

- JWH015

- JWH133

- MDA7

- MDA19

Endocannabinoid modulators

Uptake Inhibitors:

- AM404

- VDM11

FAAH inhibitors:

- Compound 17

- OL135

- URB597

MGL inhibitors:

- JZL184

- URB602

FAAH $=$ fatty-acid amide hydrolase; MGL $=$ monoacylglycerol lipase; $\mathrm{THC}=$ tetrahydrocannabinol.

binoids and modulation of the endocannabinoid system on neuropathic pain.

Models of surgically-induced traumatic nerve injury

Cannabinoids suppress neuropathic nociception in at least nine different animal models of surgically-induced traumatic nerve or nervous system injury. Here, we review the literature with a focus on uncovering effects of different classes of cannabinoids on both neuropathic nociception and central sensitization in each model. We also consider the impact of nerve injury on the endocannabinoid signaling system. Where applicable, we review effects of neuropathic injury on levels of endocannabinoids and related lipid mediators, and we describe regulatory changes in $\mathrm{CB}_{1}$ and $\mathrm{CB}_{2}$ receptors induced by nerve injury. Finally, we will consider implications of the preclinical findings for cannabinoid-based pharmacotherapies for neuropathic pain in humans.

\section{Chronic constriction injury}

Chronic constriction injury (CCI) produces mechanical allodynia as well as thermal allodynia and hyperalgesia in the ipsilateral paw as early as 2 days postsurgery. ${ }^{37}$ Initial reports failed to find mechanical hyperalgesia, although several of the reviewed articles report its presence after surgery. Very few studies have investigated the presence of cold allodynia after this nerve injury; however, those that have evaluated its presence uniformly demonstrate efficacy of cannabinoids in suppressing cold allodynia. $\mathrm{CB}_{1}$ receptors are upregulated in the spinal cord after CCI; these effects are believed to be modulated by tyrosine kinase ${ }^{38}$ and glucocorticoid $^{39}$ receptors. Not surprisingly, several classes of cannabinoids have been shown to suppress CCI-induced neuropathic nociception in rodents and include mixed cannabinoid agonists, which target both $\mathrm{CB}_{1}$ and $\mathrm{CB}_{2}$ receptors, $\mathrm{CB}_{2}$ selective agonists, and modulators of the endocannabinoid system that inhibit FAAH or MGL (Tables 2 and 3).

Chronic administration of synthetic analogues of natural cannabinoid ligands containing cannabidiol (CBD) attenuate or reverse established thermal and mechanical hyperalgesia in the CCI model. However, anti-hyperalgesic effects observed with these compounds are likely to be independent of cannabinoid receptors, and may be mediated through TRPV1. Those studies investigating pharmacological specificity have demonstrated blockade with the TRPV1 antagonist capsazepine, but not a cannabinoid $\mathrm{CB}_{1}$ or $\mathrm{CB}_{2}$ antagonist. ${ }^{40,41}$ The $\mathrm{CB}_{1}$ specific antagonist SR141716 has been tested in this model with disparate results. SR141716, administered acutely, is pro-hyperalgesic and pro-allodynic in this model. ${ }^{42}$ However, SR141716 (by mouth), administered chronically, suppresses thermal and mechanical hyperalgesia in both rats and $\mathrm{CB}_{1}{ }^{+/+}$mice, while failing to produce an effect in $\mathrm{CB}_{1}{ }^{-/-}$mice. ${ }^{43}$ These reports are interspersed with a host of articles that indicate no antinociceptive or pro-nociceptive effects of either $\mathrm{CB}_{1}$ or $\mathrm{CB}_{2}$ antagonists, administered alone. Thus, it is important to emphasize that the behavioral phenotype induced by antagonist treatment may depend on the level of endocannabinoid tone present in the system, the injection paradigm (chronic 
Table 2. Antinociceptive Effects of Cannabinoids after Chronic Constriction Injury in Rats

\begin{tabular}{|c|c|c|c|c|c|c|c|c|}
\hline & & & & & & Mecha & nism & \\
\hline & Compound & Route & Thermal & Hyperalgesia & Allodynia & $\mathrm{CB}_{1}$ & $\mathrm{CB}_{2}$ & Ref No \\
\hline Synthetic & eCBD & p.o. & Yes & - & Yes & - & - & 41 \\
\hline Analogues of & & p.o. & Yes & - & Yes & No (SR1 i.p.) & No (SR2 i.p.) & \\
\hline Natural & CBD & p.o. & No & No & - & - & - & 40 \\
\hline Cannabinoid & & & No & - & No & - & - & 41 \\
\hline Ligands & & p.o. & Yes & - & Yes & - & - & 41 \\
\hline & & & Yes & Yes & - & No (SR1 i.p.) & No (SR2 p.o.) & 40 \\
\hline & $\Delta^{9}-\mathrm{THC}$ & p.o. & Yes & - & Yes & - & - & 41,171 \\
\hline & & p.o. & No & - & No & - & - & 41 \\
\hline & $\mathrm{pCBD}+\mathrm{pTHC}$ & p.o. & Yes & - & Yes & - & - & 41 \\
\hline Mixed $\mathrm{CB}_{1} / \mathrm{CB}_{2}$ & BAY $59-3074$ & p.o. & Yes & - & Yes & - & - & 78 \\
\hline agonists & CР55,940 & i.p. & Yes & - & Yes & - & - & 171 \\
\hline & WIN55,212-2 & s.c. & No & No & - & - & - & 48 \\
\hline & & & - & No & No & - & - & 172 \\
\hline & & & - & Yes & - & - & - & 173 \\
\hline & & s.c. ${ }^{\ddagger}$ & Yes & Yes & - & - & - & 48 \\
\hline & & & Yes & - & Yes & Yes (SR1 i.v.) & Yes (SR2 i.v.) & 54 \\
\hline & & & Yes & - & Yes & Yes (SR1 s.c. & - & 57 \\
\hline & & i.p. & Yes-heat & Yes & Yes & Yes* (SR1 i.p.) & - & 42 \\
\hline & & & Yes-cold & & & & & \\
\hline & & & Yes & - & Yes & Yes (SR1 i.p.) & - & 119 \\
\hline & & i.v. & Yes & - & - & - & - & 47 \\
\hline & & i.t. & $\mathrm{Yes}^{\dagger}$ & - & $\mathrm{Yes}^{\dagger}$ & Yes (AM281 i.t.) & - & 38 \\
\hline & & & - & Yes & - & - & - & 173 \\
\hline & & i.pl. & $\operatorname{Yes}^{\dagger}$ & - & $\operatorname{Yes}^{\dagger}$ & - & - & 119 \\
\hline $\mathrm{CB}_{2}$ Agonists & A-796260 & i.p. & - & - & Yes & - & - & 174 \\
\hline & A- 836339 & i.p. & - & - & Yes & - & Yes (SR2 i.p.) & 51 \\
\hline & & i.p. ${ }^{\ddagger}$ & - & - & Yes & - & - & \\
\hline & $\begin{array}{c}\text { GW405833 } \\
\text { (L768242) }\end{array}$ & i.p. & - & - & Yes & - & - & 50 \\
\hline Endocannabinoid & AM404 & s.c. & No & - & No & - & - & 52 \\
\hline Modulators & & & Yes & - & Yes & - & - & 57 \\
\hline & & & Yes & - & - & - & - & 53 \\
\hline & & s.c. ${ }^{\neq}$ & Yes & - & Yes & Yes (SR1 i.p.) & Yes (SR2 i.p.) & 52 \\
\hline & & & Yes & Yes & - & Yes (SR1 i.p.) & No (SR2 i.p.) & 53 \\
\hline & & & Yes & - & Yes & Yes (SR1 i.v.) & No (SR2 i.v.) & 54 \\
\hline & & & Yes & - & Yes & Yes (SR1 s.c. & - & 57 \\
\hline & VDM11 & s.c. ${ }^{\neq}$ & Yes & - & Yes & - & - & 52 \\
\hline
\end{tabular}

eCBD = Cannabis sativa with high CBD content; i.p. = intraperitoneal; i.pl. $=$ intraplantar; i.t. $=$ intrathecal; i.v. $=$ intravenous; $\mathrm{pCBD}$ $=$ pure cannabidiol; p.o. $=$ per orem; pTHC $=$ pure $\Delta^{9}$-tetrahydrocannabinol; s.c. $=$ subcutaneous; SR1 $=$ SR141716; SR2 $=$ SR144528. *Only tested in thermal hyperalgesia and mechanical allodynia; ${ }^{\dagger}$ increased measurements in contralateral paw at dose(s) tested; ${ }^{\ddagger}$ chronic postinjury.

vs acute), and the presence of regulatory changes in cannabinoid receptors or endocannabinoids.

Several mixed cannabinoid $\mathrm{CB}_{1} / \mathrm{CB}_{2}$ agonists have been shown to suppress all forms of neuropathic nociception observed in the CCI model, primarily through $\mathrm{CB}_{1}$ mediated mechanisms. Several studies, including the original study by Herzberg et al. ${ }^{42}$ were conducted before the development of a $\mathrm{CB}_{2}$ antagonist and recognition that $\mathrm{CB}_{2}$ receptor mechanisms modulate neuropathic pain. ${ }^{44}$ Mixed $\mathrm{CB}_{1} / \mathrm{CB}_{2}$ agonists, such as CP55,940 or WIN55,212-2, typically act as $\mathrm{CB}_{1}$ selective agonists after systemic administration, ${ }^{45}$ although $\mathrm{CB}_{2}$ mediated effects may be unmasked after administration of $\mathrm{CB}_{2}$ selective agents or after local administra- tion of the same compounds. A neurophysiological basis for these findings is derived from the observation that WIN55,212-2 (intravenously) dose dependently inhibits windup ${ }^{46}$ as well as CCI-induced increases in spontaneous firing ${ }^{47}$ of spinal wide dynamic range (WDR) neurons through a $\mathrm{CB}_{1}$ dependent mechanism. Spontaneous firing of WDR neurons is believed to contribute to behavioral hypersensitivity and neuronal sensitization in neuropathic pain states. WIN55,212-2 also normalizes prostaglandin $\mathrm{E}_{2}$ levels and nitric oxide activity, two mediators of neuropathic pain that are increased after $\mathrm{CCI}^{48}$

Multiple $\mathrm{CB}_{2}$ selective agonists have been demonstrated to suppress CCI-induced mechanical allodynia, 


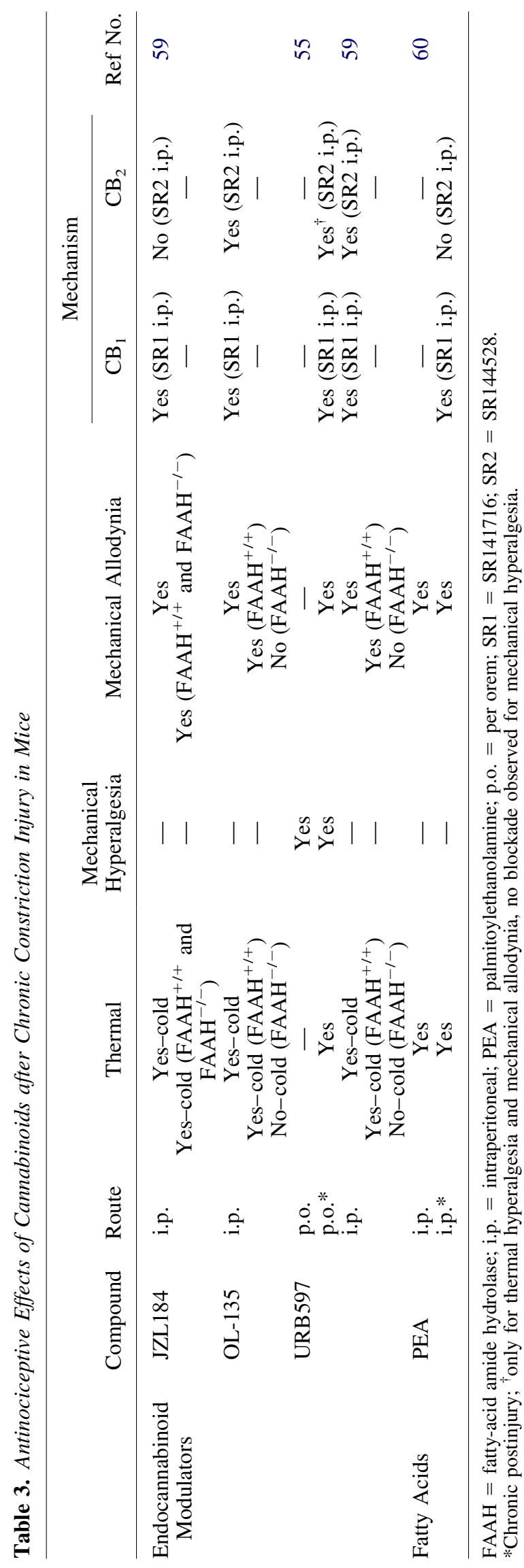

although pharmacological specificity has not been consistently assessed (Table 2). Thus, it is noteworthy that $\mathrm{CB}_{2}$ receptor mRNA is upregulated in the lumbar spinal cord after CCI. This upregulation is restricted to nonneuronal cells (e.g., glia). ${ }^{49}$ Interestingly, GW405833, a CB 2 specific agonist, also reduces depression-like behavior associated with this mononeuropathy in the forced swim test. ${ }^{50}$ Tolerance, a feature that may contribute to loss of analgesic efficacy of currently available analgesics, failed to develop after repeated administration of the $\mathrm{CB}_{2}$ specific agonist, A-836339. Thus, $\mathrm{CB}_{2}$ agonists may show therapeutic potential for suppressing neuropathic pain without producing tolerance when administered either alone or as adjuncts to exisiting treatments. ${ }^{51}$

Endocannabinoid modulators suppress neuropathic pain symptoms associated with CCI (Tables 2 and 3). AM404, an endocannabinoid transport inhibitor, increases accumulation and, hence, bioavailability, of anandamide (and potentially other endocannabinoids) through a mechanism that remains incompletely understood. AM404 also normalizes CCI-induced changes innitric oxide activity, ${ }^{52,53}$ cyclooxygenase- $2^{53}$ activity, cytokine levels (e.g., tumor necrosis factor- $\alpha$ and interleukin-10), ${ }^{52}$ and nuclear factor- $\kappa \mathrm{B}^{52}$ levels. In CCI rats, chronic administration of either AM404 or URB597 suppresses plasma extravasation, a condition associated with neuropeptide release at peripheral levels. ${ }^{54,55}$ AM404, administered chronically or acutely, does not affect locomotor behavior, indicating a low propensity of this agent to produce unwanted motor side effects associated with direct activation of $\mathrm{CB}_{1}$ receptors. ${ }^{52,53}$

$\mathrm{CCI}$ produces regulatory changes in endocannabinoid levels. CCI increases AEA and 2-AG levels in the periaqueductal gray and rostral ventromedial medulla, sites implicated in the descending modulation of pain. ${ }^{56} \mathrm{CCI}$ also increases levels of endogenous AEA, but not 2-AG, in the dorsal raphe, which was an observation that may help explain the antihyperalgesic efficacy of an anandamide transport inhibitor in this model..$^{57} \mathrm{CCI}$ increases serotonin (5-HT) levels in the dorsal raphe and this effect was suppressed by both WIN55,212-2 and AM404 in a $\mathrm{CB}_{1}$ dependent manner. ${ }^{57} \mathrm{CCI}$-induced Fos expression was observed in response to non-noxious mechanical stimulation in spinal cord laminae I and II, the site of termination of $\mathrm{A} \delta$ and $\mathrm{C}$ fibers, which carry nociceptive sensory information from the periphery to the CNS. Lower levels of evoked Fos expression were observed in laminae III and IV of CCI rats. Chronic administration of AM404 significantly decreased CCI-induced Fos expression in the lumbar spinal cord through $\mathrm{CB}_{1} / \mathrm{CB}_{2}$ and TRPV1-mediated mechanisms. ${ }^{58}$ Antinociceptive effects of FAAH inhibitors (OL135 and URB597) have also been reported in mice after CCI. OL135 and URB597 attenuate cold and mechanical allodynia in a manner that is dependent on activation of both $\mathrm{CB}_{1}$ and $\mathrm{CB}_{2}$ recep- 
tors. ${ }^{59}$ In addition, both OL135 and URB597 are antinociceptive in $\mathrm{FAAH}^{+/+}$mice, but fail to produce an effect in $\mathrm{FAAH}^{-1-}$ mice. $^{59}$ The novel MGL inhibitor, JZL184, attenuates CCI-induced mechanical and cold allodynia through indirect activation of the $\mathrm{CB}_{1}$ receptor; JZL184 was efficacious in attenuating neuropathic nociception in both $\mathrm{FAAH}^{+/+}$and $\mathrm{FAAH}^{-/-}$mice. ${ }^{59}$ The fatty acid PEA, administered chronically, attenuated the development of thermal hyperalgesia and mechanical allodynia in the CCI model through $\mathrm{CB}_{1}$, PPAR $\gamma$, and TRPV1mediated mechanisms. ${ }^{60}$ Chronic administration of PEA also normalized levels of three neutrophic factors (nerve growth factor, glial cell line-derived neurotrophic factor, and neurotrophin-3) that were increased by CCI. ${ }^{60}$ Thus, activation of $\mathrm{CB}_{1}$ and $\mathrm{CB}_{2}$ receptors, as well as pharmacological manipulation of endocannabinoid accumulation or breakdown, suppresses neuropathic nociception in rodents.

\section{Partial sciatic nerve ligation (Seltzer Model)}

Mechanical hyperalgesia and allodynia are observed after partial ligation of the sciatic nerve. ${ }^{61}$ Thermal hyperalgesia was present in all studies reviewed here that evaluated this measure with one exception. ${ }^{62}$ Only two studies we reviewed examined the presence of cold allodynia after partial sciatic nerve ligation; the first study found that both $\mathrm{CB}_{2}^{+/+}$and $\mathrm{CB}_{2}{ }^{-1-}$ mice showed evidence of cold allodynia after surgery. ${ }^{63}$ Cold allodynia has also been reported in rats after partial sciatic nerve ligation. ${ }^{64}$ All classes of cannabinoids evaluated produced anti-allodynic and antihyperalgesic effects in the Seltzer model (Table 4).

Pro-hyperalgesic effects of SR141716 and SR144528 have been reported in the Seltzer model, ${ }^{65}$ indicating a potential alteration in endocannabinoid tone after nerve injury. No other articles we reviewed reported similar effects of cannabinoid antagonists administered alone in this model. Exogenously applied endocannabinoids, AEA and 2-AG, suppress changes in neuropathic nociception induced by partial sciatic nerve ligation. Interestingly, AEA produced anti-hyperalgesic and anti-allodynic effects through a $\mathrm{CB}_{1}$ mechanism, ${ }^{65,66}$ whereas 2-AG produced anti-hyperalgesic and anti-allodynic effects through activation of both peripheral $\mathrm{CB}_{1}$ and $\mathrm{CB}_{2}$ receptors. ${ }^{67} \mathrm{AEA}$ and PEA exerts effects, at least in part, through a peripheral mechanism; both fatty-acid amides suppressed release of calcitonin gene-related peptide and somatostatin evoked by the irritant resiniferotoxin without altering peptide release under basal conditions. ${ }^{65}$ Antihyperalgesic effects of AEA and PEA were blocked by a $\mathrm{CB}_{1}$ and $\mathrm{CB}_{2}$ antagonist, respectively. ${ }^{65}$ One limitation with studies using exogenous administration of endocannabinoids is that they do not imply that endocannabinoids are released under physiological conditions to produce these effects. Several studies report efficacy of mixed canna- binoid $\mathrm{CB}_{1} / \mathrm{CB}_{2}$ agonists in this model, although $\mathrm{CNS}$ side effects were nonetheless observed in the same dose range that resulted in full reversal of neuropathic nociception. ${ }^{68}$ Ajulemic acid (CT-3), which was developed as a peripherally restricted cannabinoid analogue, also produced activity in the tetrad, but antihyperalgesic effects occurred at doses lower than those producing side effects. ${ }^{69}$

Structurally distinct $\mathrm{CB}_{2}$ specific agonists are efficacious in suppressing neuropathic nociception in this model. Moreover, $\mathrm{CB}_{2}$ receptors in the spinal cord contribute to $\mathrm{CB}_{2}$ mediated suppression of mechanical allodynia. ${ }^{70} \mathrm{CB}_{2}{ }^{-/-}$mice reportedly develop thermal hyperalgesia and mechanical allodynia in the contralateral paw after surgery, whereas $\mathrm{CB}_{2}{ }^{+/+}$do not. ${ }^{63}$ Microglia and astrocyte expression in the spinal dorsal horn is observed in both $\mathrm{CB}_{2}^{-/-}$and $\mathrm{CB}_{2}^{+/+}$mice ipsilateral to nerve injury. However, $\mathrm{CB}_{2}{ }^{-1-}$ mice notably exhibit increased microglial and astrocyte expression in the contralateral spinal dorsal horn, a mechanism which may help to explain differences in neuropathic nociception between wild-types and knockouts. ${ }^{63}$ Further support for this hypothesis is derived from the observation that overexpression of the $\mathrm{CB}_{2}$ receptor attenuated enhanced expression of microglia. ${ }^{63}$ These results suggest that genetic disruption of the $\mathrm{CB}_{2}$ receptor has a disinhibitory effect on the responses of glial cells after partial sciatic nerve ligation. The cytokine, interferon-gamma, is produced by astrocytes and neurons ipsilateral to injury in both $\mathrm{CB}_{2}{ }^{+/+}$ and $\mathrm{CB}_{2}{ }^{-1-}$ mice. However, $\mathrm{CB}_{2}{ }^{-1-}$ mice exposed to partial sciatic nerve ligation exhibit interferon-gamma immunoreactivity in the spinal dorsal horn contralateral to injury. Interferon- $\gamma^{-1-} / \mathrm{CB}_{2}^{-1-}$ mice showed no evidence of neuropathic nociception when the contralateral paw was stimulated after surgery, suggesting that immune responses underlie neuropathic pain responses observable in the contralateral paw of $\mathrm{CB}_{2}^{-1-}$ mice. ${ }^{71} \mathrm{De}-$ letion of a putative novel cannabinoid receptor, GPR55, is also associated with the failure to develop mechanical hyperalgesia after partial sciatic nerve ligation. ${ }^{72}$

Compounds targeting three distinct mechanisms for modulating endocannabinoid levels also suppress neuropathic nociception after partial sciatic nerve ligation. The transport inhibitor AM404, administered systemically, suppressed mechanical allodynia in a $\mathrm{CB}_{1}$ dependent manner without producing motor effects. ${ }^{73}$ The FAAH inhibitor URB597, administered locally in the paw, ${ }^{67}$ but not systemically, ${ }^{62}$ suppressed both thermal hyperalgesia and mechanical allodynia through a $\mathrm{CB}_{1}$ mechanism. The MGL inhibitor URB602 (which can not be used systemically as a selective MGL inhibitor), administered locally in the paw, also suppressed neuropathic nociception in this model through activation of both $\mathrm{CB}_{1}$ and $\mathrm{CB}_{2}$ receptors. ${ }^{67}$ The fatty-acid analogue of PEA, L-29, also suppressed thermal hyperalgesia and mechanical al- 
Table 4. Antinociceptive Effects of Cannabinoids after Partial Sciatic Nerve Ligation (Seltzer Model)

\begin{tabular}{|c|c|c|c|c|c|c|c|c|}
\hline & \multirow[b]{2}{*}{ Compound } & \multirow[b]{2}{*}{ Route } & \multirow[b]{2}{*}{ Thermal } & \multirow{2}{*}{$\begin{array}{l}\text { Mechanical } \\
\text { Hyperalgesia }\end{array}$} & \multirow{2}{*}{$\begin{array}{l}\text { Mechanical } \\
\text { Allodynia }\end{array}$} & \multicolumn{2}{|c|}{ Mechanism } & \multirow[b]{2}{*}{ Ref No. } \\
\hline & & & & & & $\mathrm{CB}_{1}$ & $\mathrm{CB}_{2}$ & \\
\hline \multirow{3}{*}{$\begin{array}{l}\text { Exogenous } \\
\quad \text { Endocannabinoids }\end{array}$} & AEA & i.p. & - & Yes & - & Yes (SR1 i.p.) & - & 65 \\
\hline & & i.paw & Yes & - & Yes & Yes (AM251 i.paw) & No (AM630 i.paw) & 66 \\
\hline & $2-\mathrm{AG}$ & i.paw & Yes & - & Yes & Yes (AM251 i.paw) & Yes (AM630 i.paw) & 67 \\
\hline \multirow{11}{*}{$\begin{array}{l}\text { Mixed } \mathrm{CB}_{1} / \mathrm{CB}_{2} \\
\text { Agonists }\end{array}$} & CT-3 (AJA) & p.o. & - & Yes & - & Yes (SR1 s.c.) & No (SR2 s.c.) & 69 \\
\hline & & i.p. & - & - & Yes & - & - & 175 \\
\hline & CP55,940 & s.c. & - & Yes & - & - & - & 68 \\
\hline & HU-210 & s.c. & - & Yes & - & - & - & 68 \\
\hline & & i.p. & NP & - & Yes & - & - & 62 \\
\hline & & & - & - & Yes & - & - & 175 \\
\hline & & i.t. & - & - & Yes & Yes (AM251 i.t.) & Yes (SR2 i.t.) & 75 \\
\hline & WIN55,212-2 & s.c. & Yes* & Yes & Yes & - & - & 68 \\
\hline & & s.c. ${ }^{\dagger}$ & Yes $^{\ddagger}$ & - & $\mathrm{Yes}^{\S}$ & Yes (AM251 chronic s.c. ${ }^{\S}$ ) & Yes (AM630 chronic s.c. $\left.{ }^{\S}\right)$ & 176 \\
\hline & & i.t. & - & Yes & - & Yes (SR1 i.t.) & - & 68 \\
\hline & & i.pl. & - & Yes & - & $\begin{array}{l}\text { Yes (blocked by SR1 s.c., } \\
\text { but not i.t.) }\end{array}$ & - & 68 \\
\hline \multirow[t]{5}{*}{$\mathrm{CB}_{2}$ Agonists } & GW405833 (L768242) & i.p. & - & Yes & - & - & - & 177 \\
\hline & & & - & - & Yes & - & - & 178 \\
\hline & JWH133 & i.p. & - & - & No & - & - & 70 \\
\hline & & i.t. & - & - & $\begin{array}{l}\text { Yes }\left(\mathrm{CB}_{2}{ }^{+/+}\right) \\
\text {No }\left(\mathrm{CB}_{2}{ }^{-l-}\right)\end{array}$ & - & - & \\
\hline & & i.paw & - & - & No & - & - & \\
\hline Endocannabinoid & AM404 & i.p. & - & - & Yes & Yes (AM251 i.p.) & - & 73 \\
\hline \multirow[t]{3}{*}{ Modulators } & URB597 & i.p. & NP & - & No & - & - & 62 \\
\hline & & i.paw & Yes & - & Yes & Yes (AM251 i.paw) & No (AM630 i.paw) & 67 \\
\hline & URB602 & i.paw & Yes & - & Yes & Yes (AM251 i.paw) & Yes (AM630 i.paw) & 67 \\
\hline \multirow[t]{4}{*}{ Fatty Acids } & L-29 & i.p. & $\begin{array}{l}\text { Yes-heat } \\
\text { No-cold }\end{array}$ & - & Yes & Yes (SR1 i.p.) & Yes $^{\mathbb{I}}$ (SR2 i.p.) & 64 \\
\hline & NaGly & s.c. & - & - & No & - & - & 75 \\
\hline & & i.t. & - & - & Yes & No (AM251 i.t.) & No (SR2 i.t.) & \\
\hline & PEA & i.p. & - & Yes & - & - & Yes (SR2 i.p.) & 65 \\
\hline
\end{tabular}

$\mathrm{AEA}=$ anandamide; $2-\mathrm{AG}=2$-arachydonoylglycerol; $\mathrm{AJA}=$ ajulemic acid; i.p. $=$ intraperitoneal; i.pl. $=$ intraplantar; i.paw $=$ intra-paw; i.t. $=$ intrathecal; NaGly $=\mathrm{N}$-arachidonoyl glycine; $\mathrm{NP}=$ not present; $\mathrm{PEA}=$ palmitoylethanolamine; p.o. $=$ per orem; s.c. $=$ subcutaneous; $\mathrm{SR} 1=\mathrm{SR} 141716 ; \mathrm{SR} 2=\mathrm{SR} 144528$

White cells $=$ tested in rats. Shaded cells $=$ tested in mice.

*Increased measurements in contralateral paw at dose(s) tested; ${ }^{\dagger}$ Chronic pre-emptive/postinjury or both; ${ }^{\ddagger}$ Postinjury; ${ }^{\S}$ Pre-emptive and postinjury combined; ${ }^{\Phi}$ Only observed blockade for mechanical allodynia, not thermal hyperalgesia. 
lodynia in the Seltzer model. The L29-induced suppression of thermal hyperalgesia was mediated by both the $\mathrm{CB}_{1}$ receptor and PPAR- $\alpha$, whereas suppression of mechanical allodynia was mediated by $\mathrm{CB}_{1} / \mathrm{CB}_{2}$ and PPAR- $\alpha$ receptors. ${ }^{64}$ PEA abolished mechanical hyperalgesia after partial sciatic nerve ligation through a mechanism that was blocked by a $\mathrm{CB}_{2}$ antagonist. ${ }^{65}$ When considering the effects of PEA, it is important to emphasize that PEA does not bind directly to $\mathrm{CB}_{2}$ receptors $^{74}$; therefore, blockade by a $\mathrm{CB}_{2}$ specific antagonist could indicate indirect modulation of receptor activity (e.g., via activation of PPAR- $\alpha$ or entourage effects) or blockade of an uncharacterized cannabinoid receptor that binds the $\mathrm{CB}_{2}$ antagonist SR144528. Intrathecal Narachidonoyl glycine (NaGly), the arachodonic acid conjugate, also attenuated mechanical allodynia in this model; however, the anti-hyperalgesic actions of this compound are independent of spinal cannabinoid receptors. ${ }^{75}$ Locally injected (intra-paw) paracetamol suppressed mechanical allodynia and thermal hyperalgesia present after partial sciatic nerve ligation, and these effects were blocked by local administration of either a $\mathrm{CB}_{1}$ or a $\mathrm{CB}_{2}$ antagonist. ${ }^{76}$ Paracetomol may undergo local metabolic transformation into AM404, resulting in increased levels of endocannabiniods.

\section{Spinal nerve ligation (SNL)}

All studies reviewed here documented the presence of mechanical allodynia after SNL. ${ }^{77}$ All studies with the exception of one ${ }^{78}$ indicated the presence of thermal hyperalgesia when animals were tested. One study evaluated the presence of cold allodynia and confirmed that animals with this injury display hypersensitivity to nonnoxious levels of cold stimulation. ${ }^{79}$ Gabapentin successfully attenuated mechanical allodynia in this model, however, several other commonly prescribed neuropathic pain medications, including amitriptyline, fluoxetine, and indomethacin failed to show similar effects. ${ }^{80}$ Thus, it is noteworthy that mixed cannabinoid agonists, cannabinoid $\mathrm{CB}_{2}$ selective agonists, and FAAH inhibitors all attenuated neuropathic nociception induced by SNL (Table 5).

As with other nerve injury models, several mixed cannabinoid $\mathrm{CB}_{1} / \mathrm{CB}_{2}$ agonists suppress hyperalgesia and allodynia produced by SNL. Acute WIN55,212-2 suppresses all forms of neuropathic nociception tested in this model. Chronic administration of WIN55,212-2 also attenuates the development of mechanical allodynia and suppresses glial activation in the spinal cord after SNL, with no overt motor side effects. ${ }^{81}$ Chronic administration of WIN55,212-2 produced anti-allodynic effects for up to 6 days after the final injection. A reappearance of glial activation was also associated with return of neuropathic nociception in this study. ${ }^{81} \mathrm{CP} 55,940$ produces antinociception in $\mathrm{CB}_{1}^{+/+}, \mathrm{CB}_{2}^{+/+}, \mathrm{CB}_{2}^{-/-}$, but not
$\mathrm{CB}_{1}{ }^{-1-}$ mice subjected to SNL, suggesting that activity at $\mathrm{CB}_{1}$ dominates the antinocieptive profile of mixed $\mathrm{CB}_{1} / \mathrm{CB}_{2}$ agonists after systemic administration. ${ }^{45} \mathrm{Spi}$ nal, but not systemic, administration of HU-210 has been reported to reduce $\mathrm{A} \delta$ fiber-evoked responses on spinal WDR neurons in both shams and SNL rats, whereas HU-210 showed no effect on C-fiber responses of SNL rats. ${ }^{82}$

SNL produces regulatory changes in $\mathrm{CB}_{1}$ mRNA and endocannabinoid levels. Increases in $\mathrm{CB}_{1}$ mRNA are observed in the uninjured (but abnormal) L4 DRG ipsilateral to injury. ${ }^{83}$ Increases in both AEA and 2-AG have also been reported in the ipsilateral injured L5, but not the uninjured L4 DRG. ${ }^{83}$ These findings collectively document the presence of regulatory changes in endocannabinoid levels associated with SNL, a finding which may contribute to the efficacy of peripherally administered cannabinoid agonists that activate $\mathrm{CB}_{1}$ receptors in this model.

Noxious stimulation (e.g., C-fiber mediated activity) induces phosphorylation of extracellular signal-regulated protein kinase (ERK) in dorsal horn neurons. The $\mathrm{CB}_{1}$ specific agonist ACEA inhibits pERK expression induced by in vitro application of capsaicin to the spinal cords of SNL rats. This observation contrasts with effects of opioids (i.e., morphine and DAMGO), which lose the ability to inhibit C-fiber induced ERK activation in the L5 spinal cord after SNL. ${ }^{84}$

Multiple $\mathrm{CB}_{2}$ specific agonists suppress neuropathic nociception induced by SNL. The $\mathrm{CB}_{2}$ agonist AM1241 suppresses both thermal hyperalgesia and mechanical allodynia after SNL in both rats ${ }^{17,44,85}$ and mice. ${ }^{44}$ $\mathrm{CB}_{1}{ }^{-1-}$ mice receiving AM1241 showed enhanced antihyperalgesia. ${ }^{44}$ An emerging body of literature now suggests that antinociceptive effects of $\mathrm{CB}_{2}$ agonists may be mediated by suppression of microglial activation. ${ }^{4}$

Evidence for upregulation of $\mathrm{CB}_{2}$ after $\mathrm{SNL}$ has been reported by several groups. $\mathrm{CB}_{2}$ mRNA was upregulated in the lumbar spinal cord after SNL, ${ }^{49}$ coincident with the expression of activated microglia. Colocalization studies, however, were not performed. Upregulation of $\mathrm{CB}_{2}$ receptor immunoreactivity on sensory afferent terminals in the spinal cord has also been reported after SNL. ${ }^{18}$ This group failed to find co-localization of $\mathrm{CB}_{2}$ with markers for glial cells in SNL rats, and concluded that $\mathrm{CB}_{2}$ receptors were upregulated on sensory neurons after spinal nerve ligation. ${ }^{18} \mathrm{CB}_{2}$ mRNA was also shown to be upregulated in the ipsilateral (vs the contralateral) spinal cord and DRG after SNL, and the presence of $\mathrm{CB}_{2}$ mRNA was confirmed in spinal cord microglial cells in culture. $^{17}$

The $\mathrm{CB}_{2}$ specific agonist GW405833, administered chronically, suppressed the development of mechanical allodynia concomitant with suppression of glial activation at the level of the spinal cord. ${ }^{81}$ The structurally 
Table 5. Antinociceptive Effects of Cannabinoids after Spinal Nerve Ligation (Traditional and Modified)

\begin{tabular}{|c|c|c|c|c|c|c|c|c|}
\hline & \multirow[b]{2}{*}{ Compound } & \multirow[b]{2}{*}{ Route } & \multirow[b]{2}{*}{ Thermal } & \multirow{2}{*}{$\begin{array}{l}\text { Mechanical } \\
\text { Hyperalgesia }\end{array}$} & \multirow[b]{2}{*}{ Mechanical Allodynia } & \multicolumn{2}{|c|}{ Mechanism } & \multirow[b]{2}{*}{ Ref No. } \\
\hline & & & & & & $\mathrm{CB}_{1}$ & $\mathrm{CB}_{2}$ & \\
\hline \multirow{8}{*}{$\begin{array}{l}\text { Mixed } \mathrm{CB}_{1} / \mathrm{CB}_{2} \\
\text { agonists }\end{array}$} & \multirow{3}{*}{$\begin{array}{l}\text { BAY 59-3074 } \\
\text { CP55,940 }\end{array}$} & \multirow{3}{*}{$\begin{array}{l}\text { p.o. } \\
\text { i.p. }\end{array}$} & NP & - & Yes & - & - & 78 \\
\hline & & & - & - & Yes & No (SR1 i.p.) & Yes (SR2 i.p.) & 179 \\
\hline & & & - & - & $\begin{array}{l}\text { Yes }\left(\mathrm{CB}_{1}^{+/+}\right) \\
\text {No }\left(\mathrm{CB}_{1}{ }^{-1-}\right) \\
\text { Yes }\left(\mathrm{CB}_{2}^{+/+} \text {and } \mathrm{CB}_{2}{ }^{-/-} \text {) }\right.\end{array}$ & - & - & 45 \\
\hline & & i.t. & - & - & Yes & No (SR1 i.t.) & - & 179 \\
\hline & \multirow[t]{4}{*}{ WIN55,212-2 } & i.p. & $\begin{array}{l}\text { Yes-heat } \\
\text { Yes-cold }\end{array}$ & - & Yes* & Yes (SR1 i.p.) & $\mathrm{No}^{\dagger}$ (SR2 i.p.) & 79 \\
\hline & & & - & - & Yes & - & - & 80 \\
\hline & & & - & - & No & - & - & 81 \\
\hline & & i.p..$^{*}$ & - & - & Yes & - & - & 81 \\
\hline \multirow[t]{9}{*}{$\mathrm{CB}_{2}$ Agonists } & \multirow[t]{4}{*}{ AM1241 } & i.p. & Yes & - & Yes & No (AM251 i.p.) & Yes (AM630 i.p.) & 44 \\
\hline & & & Yes $\left(\mathrm{CB}_{1}^{+/+}\right.$and $\left.\mathrm{CB}_{1}^{-l-}\right)$ & - & Yes $\left(\mathrm{CB}_{1}^{+/+}\right.$and $\left.\mathrm{CB}_{1}^{-/-}\right)$ & No (AM251 i.p.) & Yes (AM630 i.p.) & 44 \\
\hline & & & - & - & Yes & - & - & 85 \\
\hline & & i.v. & - & - & Yes & - & Yes (SR2 i.p.) & 17 \\
\hline & Compound 27 & i.p. & - & - & Yes & - & - & 180 \\
\hline & GW405833 (L768242) & i.p. & - & - & Yes & - & - & 81 \\
\hline & L768242 (GW405833) & i.p. & - & - & Yes & - & - & 17 \\
\hline & MDA19 & i.p. & - & - & Yes & - & Yes (AM630 i.p.) & 181 \\
\hline & MDA7 & i.p. & - & - & Yes & No (AM251 i.p.) & Yes (AM630 i.p.) & 85 \\
\hline Endocannabinoid & Compound 17 & i.v. & - & - & Yes & - & - & 90 \\
\hline Modulators & OL135 & i.p. & - & - & Yes & No (SR1 i.p.) & Yes (SR2 i.p.) & 91 \\
\hline
\end{tabular}

i.v. $=$ intravenous; i.p. $=$ intraperitoneal; p.o. $=$ per orem; i.t. $=$ intrathecal; $\mathrm{NP}=$ not present; SR1 $=\mathrm{SR} 141716 ; \mathrm{SR} 2=\mathrm{SR} 144528$

White cells $=$ tested in rats. Shaded cells $=$ tested in mice.

*Increased measurements in contralateral paw at dose(s) tested; ${ }^{\dagger}$ Only cold allodynia tested; ${ }^{\ddagger}$ Chronic postinjury. 
distinct $\mathrm{CB}_{2}$ specific agonist, JWH133, also attenuates mechanically-evoked responses of WDR neurons in both naive and spinal nerve ligated rats. ${ }^{86}$ Local injection of JWH133 into the ventroposterolateral nucleus of the thalamus attenuated spontaneous and mechanicallyevoked neuronal activity in SNL, but not sham rats, in a $\mathrm{CB}_{2}$ dependent manner. ${ }^{87}$ Thus, $\mathrm{CB}_{2}$ receptor activation may exert little functional control under nonpathological conditions. Systemic and spinal administration of the novel $\mathrm{CB}_{2}$ agonist, $\mathrm{A}-836339$, also attenuates spontaneous and mechanically-evoked neuronal firing of spinal WDR neurons in a $\mathrm{CB}_{2}$ dependent manner in SNL, but not sham rats. ${ }^{88}$ Interestingly, pretreatment with the $\mathrm{CB}_{1}$ antagonist, SR141716, enhanced the effects of A-836339 when applied to the $\mathrm{L} 5 \mathrm{DRG},{ }^{88}$ indicating that blockade of $\mathrm{CB}_{1}$ receptors enhanced the antinociceptive effects of a $\mathrm{CB}_{2}$ agonist, as previously reported. ${ }^{89}$

Two endocannabinoid modulators have been evaluated behaviorally in this model. Compound 17, a novel FAAH inhibitor, reversed mechanical allodynia in SNL rats with the same potency as a 5-fold higher dose of gabapentin..$^{90}$ In addition, OL135, a compound that accesses the CNS and inhibits FAAH, suppressed mechan-

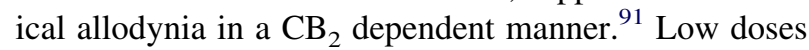
of locally injected URB597 reduced mechanicallyevoked responses of WDR neurons and increased endocannabinoid levels in ipsilateral paw tissue of shamoperated rats. ${ }^{92}$ A 4 -fold higher dose was required for reduction of mechanically-evoked WDR neuronal responses in SNL rats; these rats showed no corresponding increase in endocannabinoid levels, suggesting that contributions of FAAH to endocannabinoid metabolism may be modified under conditions of neuropathic nociception. ${ }^{92}$ The antinociceptive effects of URB597 were blocked by a $\mathrm{CB}_{1}$ specific antagonist in both sham and SNL rats. ${ }^{92}$ In the same study, spinal administration of URB597 was equally efficacious at attenuating mechanically-evoked responses and increasing levels of endogenous cannabinoids in SNL and sham rats, and these effects were $\mathrm{CB}_{1}$ mediated. ${ }^{92}$

\section{Other nerve injury models}

Cannabinoids alleviate neuropathic nociception in several other injury models. These studies support a role for $\mathrm{CB}_{1}$ in the anti-hyperalgesic effects of cannabinoids, although pharmacological specificity has not been consistently assessed in the literature and high doses of cannabinoid agonists can produce motor side effects, which complicate interpretation of behavioral studies. Chronic constriction injury of the infraorbital nerve results in thermal hyperalgesia and mechanical allodynia (as measured by head withdrawals) ipsilateral to the site of injury. ${ }^{93}$ WIN55,212-2 and HU-210 increased mechanical withdrawal responses and thermal withdrawal latencies on the ipsilateral side of the head in this mo- del. ${ }^{94}$ WIN55,212-2 was more efficacious in suppressing mechanical allodynia versus thermal hyperalgesia in the chronic constriction injury of the infraorbital nerve model. High antihyperalgesic doses of WIN55,212-2 decreased rotarod latencies and body temperature, whereas HU210, at the singular low dose used $(10 \mu \mathrm{g} / \mathrm{kg})$, had no effect on these dependent measures. $\mathrm{CB}_{1}$ receptor upregulation was observed in both the ipsilateral and contralateral superficial layer of the trigeminal caudal nucleus, and this effect was greater on the ipsilateral side. These and earlier findings from the same group ${ }^{95}$ indicate that cannabinoids are negative modulators of nociceptive transmission at the superficial layer of the trigeminal caudal subnucleus.

$\mathrm{CB}_{2}$ receptor immunoreactivity ${ }^{96}$ is increased in the ipsilateral dorsal horn after $L 5$ spinal nerve transection. ${ }^{97}$ Importantly, co-localization of $\mathrm{CB}_{2}$ immunoreactivity with markers of microglia and perivascular cells was observed on day 4 postsurgery. ${ }^{96}$ In this study, neither neuronal cells nor astrocyctes expressed immunoreactivity for $\mathrm{CB}_{2}$ receptors. ${ }^{96} \mathrm{CP} 55,940$ reversed mechanical allodynia in this model $1 \mathrm{~h}$ after a second intrathecal injection, although this dosing paradigm was also associated with motor effects. ${ }^{96}$ Intrathecal JWH015 dose dependently suppressed behavioral hypersensitivity after a second injection, indicating a cumulative anti-allodynic effect of this drug. Intrathecal JWH015 reduced spinal nerve transection-induced increases in activated microglia in a $\mathrm{CB}_{2}$ dependent manner, further supporting a role for nonneuronal $\mathrm{CB}_{2}$ receptors in antihyperalesic effects of $\mathrm{CB}_{2}$ agonists. $^{96}$

Two models developed by Walczak et al. ${ }^{98,99}$ involved injuries to the saphenous nerve in rats and mice, respectively. The advantage of injuring the saphenous nerve in comparison with other nerves is that the saphenous nerve is an exclusively sensory nerve, whereas other nerve injury models typically target nerves that subserve both sensory and motor functions. The first model was produced in rats by saphenous partial nerve ligation, which involves trapping $30 \%$ to $50 \%$ of the saphenous nerve in a tight ligature. ${ }^{98}$ Saphenous partial nerve ligation rats presented with all symptoms except mechanical hyperalgesia, which was present inconsistently throughout testing. WIN55,212-2, administered systemically, suppressed all forms of hyperalgesia and allodynia present. ${ }^{98}$ In rats, saphenous partial nerve ligation increased $\mu$-opioid, $\mathrm{CB}_{1}$, and $\mathrm{CB}_{2}$ receptor protein in ipsilateral hind paw skin, DRG, and lumbar spinal cord. ${ }^{98}$ In a second injury model, chronic constriction of the saphenous nerve was accomplished by tying two loose ligatures around the saphenous nerve in mice. ${ }^{99}$ Systemic WIN55,212-2 suppressed all forms of neuropathic nociception present in this model, including thermal hyperagesia, cold allodynia, mechanical hyperalgesia, and mechanical allodynia. ${ }^{99} \mathrm{Mu}$-opioid, $\mathrm{CB}_{1}$ and $\mathrm{CB}_{2}$ receptor 
protein was increased in the ipsilateral spinal cord and hind paw skin at 7 days postsurgery. ${ }^{99}$ In addition, increased $\mathrm{CB}_{1}$ receptor protein was observed in contralateral hind paw skin 7 days postsurgery and increased $\mathrm{CB}_{2}$ receptor expression was observed in the contralateral spinal cord 1 and 7 days postsurgery. The neurobiological rearrangement of cannabinoid and mu-opioid receptors may contribute to the antinociceptive efficacy of WIN55,212-2 and morphine in this model.

The spared nerve injury (SNI) model reliably produces thermal hyperalgesia and mechanical allodynia in studies that tested for both measures. Initial reports of the SNI model indicated the presence of cold allodynia and mechanical hyperalgesia, ${ }^{100}$ but none of the articles reviewed here assessed these behaviors in conjunction with cannabinoid treatment. Standard analgesics (e.g., morphine, gabapentin, amitryptiline) are efficacious in treating neuropathic nociception resulting from a crush injury of the sciatic nerve, but showed limited efficacy after SNI. ${ }^{101}$ Two mixed cannabinoid $\mathrm{CB}_{1} / \mathrm{CB}_{2}$ agonists have been tested in this model. Acute WIN55,212-2 suppressed thermal hyperalgesia and mechanical allodynia in both mice lacking $\mathrm{CB}_{1}$ receptors in primary nociceptors (SNS-CB ${ }_{1}{ }^{-}$) and their wild-type controls; however, differences in the antinociceptive effects of WIN55,212-2 were observed between genotypes, and these effects were greater with mechanical than thermal sensitivity. Comparable responses to WIN55,212-2 were only observed at doses high enough to induce sedation and rigidity in all mice. $\mathrm{SNS}-\mathrm{CB}_{1}{ }^{-}$ mice showed exaggerated sensitivity to noxious levels of mechanical stimulation and a cold plate relative to their wild-type counterparts, whereas differential sensitivity was not observed between genotypes with non-noxious levels of mechanical stimulation and noxious levels of thermal stimulation. ${ }^{7}$ Thus, $\mathrm{CB}_{1}$ receptors on nociceptors in the periphery account for much of the antinociceptive effects of cannabinoids. ${ }^{7}$ A dose-escalation study with BAY 59-3074 in the SNI model indicated that tolerance rapidly develops to side effects observed after chronic administration (e.g., hypothermia), whereas no loss in analgesic efficacy was observed. ${ }^{78}$

Spinal cord injury $(\mathrm{SCI})^{102}$ produces mechanical hyperalgesia and allodynia. WIN55,212-2 is the only compound that has been evaluated in the SCI model. Acute WIN55,212-2, administered systemically, suppressed SCI-induced mechanical allodynia in a $\mathrm{CB}_{1}$ dependent manner, although other parameters of neuropathic pain were not assessed. ${ }^{103}$ Unlike morphine, chronic administration of WIN55,212-2 reduced mechanical allodynia in the SCI model with no decrease in effectiveness over time. ${ }^{104}$

Tibial nerve injury is performed by unilaterally axotomizing the tibial branch of the sciatic nerve. Mechanical allodynia and thermal hyperalgesia were present in the initial study describing this technique, ${ }^{105}$ as well as the study we reviewed. Systemic BAY 59-3074 was shown to attenuate both forms of neuropathic nociception, although pharmacological specificity was not assessed. ${ }^{78}$ Tibial nerve injury injury resulted in an upregulation of $\mathrm{CB}_{1}$ receptor mRNA in the contralateral thalamus on day 1 postsurgery, ${ }^{106}$ indicating cannabinoid receptor regulation within an important relay nucleus in the ascending pain pathway.

\section{Disease-related models of neuropathic pain}

Cannabinoid agonists have been evaluated in animal models of disease-related neuropathic pain, although pharmacological specificity has not been consistently assessed. Herein, we review effects of cannabinoids in preclinical models of neuropathic pain induced by diabetes, chemotherapeutic treatment, HIV/antiretroviral treatment, demyelination disorders, multiple sclerosis (MS), and postherpetic neuralgia.

\section{Single injection of streptozotocin-induced diabetic neuropathy}

Diabetic neuropathy induced by a single injection of streptozotocin (STZ) resulted in increased sensitivity to noxious and non-noxious levels of mechanical stimulation, and failed to induce thermal hyperalgesia in the studies reviewed here (Table 6). None of the studies we reviewed evaluated the presence of cold allodynia. 2-Methyl-2'-F-anandamide (Met-F-AEA), a $\mathrm{CB}_{1}$ specific agonist based on the structure of anandamide, the mixed cannabinoid agonist WIN55,212-2, and the $\mathrm{CB}_{2}$ specific agonist AM1241, administered chronically, suppressed mechanical hyperalgesia associated with STZinduced diabetic neuropathy. However, mediation by cannabinoid receptors has not been assessed for agonists tested in this model. Daily pretreatment with indomethacin (cyclooxygenase-1 inhibitor) or L-NG-nitro arginine ([L-NOArg] nonselective nitric oxide synthase inhibitor) increased the antihyperalgesic actions of low doses of WIN55,212-2, AM1241, and Met-F-AEA in STZ rats to a greater extent than the cannabinoid administered alone, suggesting the presence of antinociceptive synergism between cannabinoid and cyclooxygenase pathways. ${ }^{107}$ Cyclooxygenase inhibitors may block oxidative metabolism of endocannabinoids, thereby increasing endocannabinoids available to interact with cannabinoid receptors.

Diabetic rats exhibit a decrease in the density of $\mathrm{CB}_{1}$ receptor protein in DRG. ${ }^{108}$ More work is necessary to determine whether this loss of cannabinoid receptors contributes to the neurodegenerative process in diabetes. Increased levels of endocannabinoids have been found in obese patients suffering from type II diabetes, ${ }^{109}$ and this effect is likely to result from downregulation of FAAH gene expression, an effect which has also been observed in adipocytes sampled from obese women. ${ }^{110}$ Lean males subjected to hyperinsulinemia show a 2 -fold increase in 
Table 6. Antinociceptive Effects of Cannabinoids in Animal Models of Disease-Related Neuropathic Pain

\begin{tabular}{|c|c|c|c|c|c|c|c|c|}
\hline \multirow[b]{2}{*}{ Model } & \multirow[b]{2}{*}{ Compound } & \multirow[b]{2}{*}{ Route } & \multirow[b]{2}{*}{ Thermal } & \multirow{2}{*}{$\begin{array}{l}\text { Mechanical } \\
\text { Hyperalgesia }\end{array}$} & \multirow{2}{*}{$\begin{array}{l}\text { Mechanical } \\
\text { Allodynia }\end{array}$} & \multicolumn{2}{|c|}{ Mechanism } & \multirow[b]{2}{*}{ Ref No. } \\
\hline & & & & & & $\mathrm{CB}_{1}$ & $\mathrm{CB}_{2}$ & \\
\hline \multirow[t]{9}{*}{ Diabetic Neuropathy } & \multirow[t]{2}{*}{ Met-F-AEA } & i.p. & - & Yes & - & - & - & \multirow[t]{2}{*}{107} \\
\hline & & i.p.* & - & Yes & - & - & - & \\
\hline & \multirow[t]{5}{*}{ WIN55,212-2 } & \multirow[t]{3}{*}{ i.p. } & NP & - & Yes & - & - & 182 \\
\hline & & & - & Yes & - & - & - & 107 \\
\hline & & & NP & - & Yes & - & - & 183 \\
\hline & & i.p.* & - & Yes & - & - & - & 107 \\
\hline & & i.paw & NP & - & Yes & - & - & 183 \\
\hline & \multirow[t]{2}{*}{ AM1241 } & i.p. & - & Yes & - & - & - & \multirow[t]{2}{*}{107} \\
\hline & & i.p.* & - & Yes & - & - & - & \\
\hline \multirow{14}{*}{$\begin{array}{l}\text { Chemotherapy-induced } \\
\text { Neuropathy }\end{array}$} & \multicolumn{8}{|l|}{ Cisplatin } \\
\hline & \multicolumn{8}{|l|}{ Paclitaxel $^{118,120}$} \\
\hline & \multirow[t]{2}{*}{ WIN55,212-2 } & i.p. & Yes & - & Yes & Yes (SR1 i.p.) & - & \multirow[t]{2}{*}{119} \\
\hline & & i.pl. & $\mathrm{Yes}^{\ddagger}$ & - & Yes $^{\ddagger}$ & - & - & \\
\hline & MDA7 & i.p. & NP & - & Yes & - & - & 85 \\
\hline & $(R, S)-\mathrm{AM} 1241$ & i.p. & NP & - & Yes & No (SR1 i.p.) & Yes (SR2 i.p.) & 89 \\
\hline & $(R)-\mathrm{AM} 1241$ & i.p. & NP & - & Yes & - & - & \\
\hline & $(S)-\mathrm{AM} 1241$ & i.p. & NP & - & No & - & - & \\
\hline & \multirow{2}{*}{\multicolumn{8}{|c|}{ Vincristine $^{121}$}} \\
\hline & & & & & & & & \\
\hline & \multirow[t]{3}{*}{ WIN55,212-2 } & i.p. & NP & - & Yes & Yes (SR1 i.p.) & Yes (SR2 i.p.) & \multirow[t]{5}{*}{122} \\
\hline & & i.t. & NP & - & Yes & Yes (SR1 i.t.) & Yes (SR2 i.t.) & \\
\hline & & i.pl. & NP & - & No & - & - & \\
\hline & $(R, S)-\mathrm{AM} 1241$ & i.p. & NP & - & Yes & No (SR1 i.p.) & Yes (SR2 i.p.) & \\
\hline \multirow[t]{7}{*}{ Other } & HIV-SN & & & & & & & \\
\hline & WIN55,212-2 & i.p.* & $\begin{array}{l}\text { NP-heat } \\
\text { NP-cold }\end{array}$ & - & $\mathrm{Yes}^{\S}$ & - & - & 124,123 \\
\hline & L-29 & i.p. ${ }^{\text {I }}$ & $\begin{array}{l}\text { NP-heat } \\
\text { NP-cold }\end{array}$ & - & Yes & Yes (SR1 i.p.) & Yes (SR2 i.p.) & 64 \\
\hline & \multicolumn{8}{|l|}{ LDPN } \\
\hline & WIN55,212-2 & i.t. & Yes & - & Yes & Yes (AM251 i.t.) & - & 125 \\
\hline & $\begin{array}{l}\mathbf{V Z V} \\
\text { L-29 }\end{array}$ & i.p. & $\begin{array}{l}\text { NP-heat } \\
\text { NP-cold }\end{array}$ & - & Yes & No (SR1 i.p.) & No (SR2 i.p.) & 64 \\
\hline & WIN55,212-2 & i.p.* & $\begin{array}{l}\text { NP-heat } \\
\text { NP-cold }\end{array}$ & - & Yes & - & - & 131 \\
\hline
\end{tabular}

$\mathrm{ddc}=$ zalcitabine; HIV-SN $=$ HIV sensory neuropathy (includes antiretroviral treatment (ddc), HIV-gp120, and HIV-gp120 + antiretroviral treatment $($ ddc) models); i.t. $=$ intrathecal; i.p. $=$ intraperitoneal; i.pl. = intraplantar; LDPN = lysolecithin-induced demyelination-associated peripheral neuropathy of saphenous nerve; NP = not present; SR1 = SR141716; SR2 = $\mathrm{SR} 144528 ; \mathrm{VZV}=$ varicella zoster virus-induced neuropathy

White cells = tested in rats. Shaded cells = tested in mice.

${ }^{*}$ Chronic postinjury; ${ }^{\dagger}$ Chronic, pre-emptive and postinjury; ${ }^{\ddagger}$ Increased measurements in contralateral paw at dose(s) tested; ${ }^{\S}$ In antiretroviral (ddc), HIV-gp120, and HIV-gp120 + antiretroviral (ddc) models; " Only tested in the antiretroviral (ddc) model. 
FAAH mRNA expression, whereas obese males subjected to the same conditions failed to show similar alterations in gene expression. ${ }^{111}$ These findings are suggestive of a negative feedback mechanism that could result in downregulation of the endocannabinoid signaling system. The $\mathrm{CB}_{1}$ antagonist rimonabant (Acomplia [Sanofi-Aventis, Montpellier, France]) ameliorates insulin resistance and decreases weight gain in patients suffering from metabolic syndromes. ${ }^{12}$ In animal models, rimonabant improves resistance to insulin through pathways that are both dependent and independent of adiponectin, a hormone important for the regulation of glucose and catabolism of fatty acids. ${ }^{13}$ Although adverse side effects have limited the potential therapeutic efficacy of Acomplia, drugs modulating the endocannabinoid system should not be disregarded as targets for potential treatments of diabetes and its associated syndromes. STZ-diabetic mice showed a progressive decline in the radial arm maze and reduced neurological scores, both of which were recovered after treatment with HU210. ${ }^{114}$ However, these effects were not blocked by a $\mathrm{CB}_{1}$ specific agonist. HU-210 did not alter the hyperglycemia index; however, it did normalize cerebral oxidative stress present in diabetic mice. ${ }^{114}$ An increase in the number of apoptotic cells and impaired neurite growth was observed in PC12 cells cultured under hyperglycemic conditions, and these were effectively treated by HU-210. ${ }^{114}$

Cannabinoids may show greater therapeutic potential for treating painful diabetic neuropathy compared to opioids. Interestingly, $\Delta^{9}$-THC exhibited enhanced antinociceptive efficacy in diabetic rats, whereas morphine showed reduced antinociceptive efficacy. ${ }^{115}$ Moreover, a non-nociceptive dose of $\Delta^{9}$-THC, administered in conjunction with morphine, enhanced the antinociceptive properties of morphine in both diabetic and naive mice. ${ }^{115}$ Thus, combinations of opioids and cannabinoids may show promise as adjunctive analgesics in humans. Diabetic rats exhibit lower levels of dynorphin and $\beta$-endorphins in CSF relative to nondiabetic rats treated under the same conditions. ${ }^{115}$ Administration of $\Delta^{9}$-THC to diabetic rats restored CSF levels of endogenous dynorphin and leu-enkephalin to levels observed after morphine administration to nondiabetic rats. ${ }^{115}$ More work is necessary to understand the mechanism underlying these observations.

\section{Chemotherapy-induced neuropathy}

Cannabinoid modulation of chemotherapy-induced neuropathy has been evaluated with agents from three major classes of chemotherapeutic agents (Table 6). A singular study has evaluated cannabinoid modulation of neuropathic nociception induced by cisplatin, a platinum-derived agent. WIN55,212-2 prevented the development of mechanical allodynia induced by cisplatin, but failed to produce an anti-emetic benefit in this study. ${ }^{116}$ It is possible that the dose of cannabinoid employed, the species used (rat) or toxicity of cisplatin-dosing paradigms may prevent detection of anti-emetic effects in this model. Cannabinoids have been shown to suppress cisplatin-induced emesis in the least shrew. ${ }^{117}$

Paclitaxel has been most frequently studied in the cannabinoid literature with three studies documenting cannabinoid-mediated suppression of paclitaxel-induced neuropathic nociception. In one study, paclitaxe ${ }^{118}$ produced mechanical allodynia starting on day 5 that continued throughout the course of study, although thermal hyperalgesia was only present from days 18 to $21 .^{119}$ WIN55,212-2 suppressed neuropathic nociception in this model, but had no effect on body temperature or immobility. WIN55,212-2-induced decreases in spontaneous motor activity were nonetheless observed. ${ }^{119} \mathrm{~A}$ more recent study using the same paclitaxel dosing para$\operatorname{digm}^{118}$ reported the presence of mechanical allodynia and the absence of thermal hyperalgesia. ${ }^{85}$ Naguib et al. ${ }^{85}$ demonstrated that a novel $\mathrm{CB}_{2}$ specific agonist, MDA7, suppressed paclitaxel-induced mechanical allodynia, although mediation by $\mathrm{CB}_{2}$ receptors was not assessed. Using the paclitaxel dosing paradigm described by Flatters and Bennett, ${ }^{120}$ mechanical allodynia, but not thermal hyperalgesia, was observed. In this model, rats showed signs of mechanical allodynia up to 72 days post-paclitaxel. ${ }^{89}$ Systemic administration of either the $\mathrm{CB}_{2}$ agonist $(R, S)$-AM1241 or its receptor-active enantiomer $(R)$-AM1241 produced $\mathrm{CB}_{2}$ mediated suppressions of paclitaxel-induced mechanical allodynia. $(S)$ AM1241, the enantiomer exhibiting lower affinity for the $\mathrm{CB}_{2}$ receptor, failed to produce an anti-allodynic effect. ${ }^{89}$ The novel cannabilactone, AM1714, also reversed mechanical allodynia associated with paclitaxel treatment in $\mathrm{a}_{2}$ dependent manner. ${ }^{89}$ Thus, both mixed $\mathrm{CB}_{1} / \mathrm{CB}_{2}$ agonists and selective $\mathrm{CB}_{2}$ agonists suppress paclitaxel-evoked mechanical allodynia.

Cannabinoid modulation of neuropathic nociception has also been evaluated with vincristine, an agent from the vinca-alkaloid class of chemotherapeutic agents. Vincristine produced mechanical allodynia, but not thermal hyperalgesia, in a 10-day injection paradigm. ${ }^{121}$ Systemic and intrathecal, but not intraplantar, WIN55,212-2 suppressed vincristine-induced mechanical allodynia through activation of $\mathrm{CB}_{1}$ and $\mathrm{CB}_{2}$ receptors. ${ }^{122}$ These findings implicate the spinal cord as an important site of action mediating anti-allodynic effects of cannabinoids. Systemic $(R, S)$-AM1241 also partially reversed vincristine-induced mechanical allodynia in a $\mathrm{CB}_{2}$ dependent manner. ${ }^{122}$ The anti-allodynic effects of WIN55,212-2 and $(R, S)$-AM1241 were observed at doses that did not produce intrinsic effects on motor behavior in the bar test. ${ }^{122}$ Our studies suggest that clinical trials of canna- 
binoids for the management of chemotherapy-evoked neuropathy are warranted.

\section{HIV-associated sensory neuropathy}

The mixed cannabinoid agonist WIN55,212-2 is an effective anti-hyperalgesic agent in three distinct animal models of HIV-associated sensory neuropathy (Table 6). Rats treated with the antiretroviral agent zalcitabine (ddc) developed mechanical allodynia that persisted up to 43 days postinjection and peaked between days 14 and $32 .{ }^{123}$ No hypersensitivity to thermal stimuli or motor deficits was observed after ddc treatment. HIV-1 has indirect interactions with neurons through its binding affinity to the external envelope binding protein gp120; researchers have exploited this mechanism to demonstrate development of peripheral neuropathy in rodents after exposure of the sciatic nerve to the HIV-1 gp120 protein. Perineural HIV-gp120 together with ddc treatment resulted in mechanical allodynia that was greater than either treatment alone; no changes in paw withdrawal latencies to thermal stimuli or motor deficits were reported. ${ }^{123}$ Thigmotaxis was present in animals receiving ddc, either alone or in conjunction with HIV-gp120, indicating the presence of anxiety-like behavior in these rats. ${ }^{123}$ Rats receiving ddc displayed modest levels of gliosis, whereas combined treatment with both HIV-gp120 and ddc increased levels of microglial activation. ${ }^{123}$ Importantly, chronic WIN55,212-2 reversed mechanical allodynia induced by either ddc treatment ${ }^{123}$ or HIV-gp120 exposure, ${ }^{124}$ whereas animals subjected to both HIV-gp120 and ddc treatment exhibited a WIN55,212-2-induced attenuation of mechanical allodynia. ${ }^{123}$ Increases in the density of microglia and astrocytes were observed in the ipsilateral dorsal horn after HIV-gp120 treatment. Thus, activated microglia may be a common target underlying cannabinoid-mediated suppressions of neuropathic nociception.

\section{Demyelination-induced neuropathy}

WIN55,212-2 has been evaluated in the lysolecithin-induced demyelination model (Table 6). Heightened sensitivity to both non-noxious and noxious mechanical stimulation is observed in lysolecithin-treated rats; this hypersensitivity emerged 5 days postexposure and peaked between 9 and 15 days postexposure. ${ }^{125}$ Recovery to baseline levels was observed by day 23 post-lysolecithin. WIN55,212-2 attenuated mechanical allodynia and thermal hyperalgesia in this model and remained efficacious for up to 1 hour postinjection. ${ }^{125}$ By contrast, DAMGO failed to produce an effect. Notably, the antihyperalgesic and anti-allodynic effects of WIN55,212-2 were reversed by a $\mathrm{CB}_{1}$ specific antagonist in both tests.

\section{MS-associated neuropathy}

Animal models of MS have been described, although to our knowledge, no study to date has evaluated canna- binoid-mediated suppression of MS-induced neuropathic nociception. Lynch et al. ${ }^{126}$ reported the presence of thermal hyperalgesia (tail immersion) and mechanical allodynia in mice that were infected with Theiler's murine encephalomyelitis virus. Interestingly, female mice showed an increased rate of development and greater allodynia than their male counterparts, a finding which mimics the greater prevalence of neuropathic pain symptoms reported by female MS patients. ${ }^{127}$ Cold and mechanical allodynia, but not thermal hyperalgesia, have been reported in a model of autoimmune encephalomyelitis in which mice were immunized with myelin oligodendrocyte glycoprotein (MOG[35-55]) ${ }^{128}$; autoimmune encephalomyelitis has been postulated to underlie the development of neuropathic pain in MS. Interestingly, a mouse model of MS (Theiler's murine encephalomyelitis virus infection) is also characterized by an upregulation of $\mathrm{CB}_{2}$ receptor mRNA and increases in levels of 2-AG and PEA. ${ }^{129}$ Animals treated subchronically with PEA showed improvements in tests of motor performance, measures that were impaired after Theiler's murine encephalomyelitis virus infection. ${ }^{129}$ Thus, we postulate that cannabinoid $\mathrm{CB}_{2}$ agonists and modulators of endogenous cannabinoids (e.g., MGL inhibitors) would exhibit anti-allodynic efficacy in this model.

\section{Postherpetic neuralgia}

Cannabinoids and fatty-acid amides suppress neuropathic nociception in an animal model of postherpetic neuralgia (Table 6). However, pharmacological specificity has not been consistently assessed in this model. Approximately $50 \%$ of rats exposed to the varicellazoster virus developed mechanical allodynia in the ipsilateral paw by 14 days postinfection; no thermal hyperalgesia or cold allodynia was observed. ${ }^{64}$ The PEA analogue L-29 suppressed mechanical allodynia in this model with an earlier onset relative to gabapentin. However, neither a $\mathrm{CB}_{1}$ nor $\mathrm{CB}_{2}$ specific antagonist blocked L-29 mediated suppression of varicella-zoster virus-induced mechanical allodynia. ${ }^{64}$ This finding is perhaps unsurprising given that PPAR- $\alpha$ mediates effects of PEA in suppressing neuronal sensitization. ${ }^{130}$ However, L-29, nonetheless, suppressed neuropathic nociception in the Seltzer model via activation of $\mathrm{CB}_{1}$ and $\mathrm{CB}_{2}$ receptors (see Table 4). Systemic WIN55,212-2, administered from days 18 to 21 postinfection, fully reversed mechanical allodynia to baseline levels in this model of postherpetic neuralgia, although pharmacological specificity was not assessed. ${ }^{131}$

\section{CANNABINOID MODULATION OF NEUROPATHIC PAIN IN CLINICAL STUDIES}

Cannabinoids have been evaluated in clinical studies for their suppression of acute, postoperative and neuro- 
pathic pain. Based on our reviews of the literature, cannabinoids exhibit their greatest efficacy when used for the management of neuropathic pain (Tables 7 and 8). ${ }^{132}$ There are approximately 460 known chemical constituents in cannabis. Thus, at the outset, it is important to emphasize that smoked cannabis is not the same as oral $\Delta^{9}$-THC or different mixtures of $\Delta^{9}$-THC and CBD (e.g., Sativex [GW Pharmaceuticals, United Kingdom] and Cannador [Institute for Clinical Research, IKF, Berlin, Germany]). Other drug delivery mechanisms (e.g., oralmucosal sprays and rectal suppositories containing cannabinoids) have been developed. Evidence to date from clinical studies suggests that these compounds show therapeutic efficacy in suppressing neuropathic pain (Table 7 and 8 ).

Three of the articles reviewed here used smoking as the route of administration, whereas the other 13 used oral preparations in the form of pills or oral-mucosal sprays. Side effects were reported in all studies in a proportion of patients receiving cannabinoid-based medications. The most frequently reported side effects were dizziness, impairment of balance, feelings of intoxication, dry mouth, and dysgeusia (most commonly observed with oral-mucosal sprays), sedation, and hunger. One study reported severe gastrointestinal effects for $10 \%$ of patients taking Sativex versus $0 \%$ reporting similar problems in the placebo group. ${ }^{133}$ However, unwanted side effects, in contrast to analgesic effects, may undergo tolerance. ${ }^{134}$ Side effects may be minimized using dosing paradigms employing low doses that are only gradually escalated. As follows, we review effects of cannabinoid-based medications in clinical studies using populations of patients presenting with neuropathic pain. Neuropathic pain induced by HIV infection and/or antiretroviral treatment, MS, brachial plexus avulsion, mixed treatment-resistant neuropathic pain, and others were considered.

\section{HIV-associated neuropathy}

Two studies have examined effects of smoked cannabis for the treatment of HIV-associated sensory neuropathy (resulting from HIV infection, dideoxynucleoside antiretroviral therapy, or both) and have reported positive results (Table 7). Abrams et al. ${ }^{135}$ reported that $52 \%$ of patients (i.e., 13 of 25 receiving cannabis cigarettes) experienced a greater than $30 \%$ reduction in pain (visual analogue scale daily ratings [VAS]). Stimulus-evoked pain testing revealed that the group receiving cannabis experienced a reduction in the area sensitive to mechanical allodynia (with a foam brush or $26 \mathrm{~g}$ von Frey hair) in the heat and capsaicin sensitization model. Moreover, CD4+, CD8+, and T-cell counts were not negatively impacted by cannabinoid treatment in HIV patients. ${ }^{136} \mathrm{In}$ 2009, Ellis et al. ${ }^{137}$ reported similar results in a crossover study using multiple concentrations of $\Delta^{9}$-THC in can- nabis cigarettes administered to patients. Cannabis was superior to a placebo in either phase of the crossover, as measured with the descriptor differential scale or VAS. This study found no changes in heart rate, blood pressure, plasma HIV RNA (viral load; VL), or blood CD4+ lymphocyte counts after cannabis treatment, suggesting that cannabis did not negatively impact the already compromised immune system in these patients. An anonymous cross-sectional questionnaire study revealed that as many as one third of patients suffering from HIV have used cannabis to treat symptoms. ${ }^{138}$ Patients reported self-dosing with marijuana primarily between $6 \mathrm{PM}$ and 12 AM. Among the symptoms improved after cannabis were appetite (97\% reported improvement), pain (improved in $94 \%$ of the patients with pain), nausea (93\% reported improvement), and anxiety (93\% reported improvement). ${ }^{138}$

Dronabinol (Marinol [Solvay Pharmaceuticals Inc, Marietta, GA]) is used to counteract AIDS-related wasting and promote appetite in patients suffering from AIDS-related anorexia. ${ }^{139}$ The benefits of $\Delta^{9}$-THC and Nabilone (Cesamet [Valeant Pharmaceuticals International, Aliso Viejo, CA]) for the treatment of chemotherapy-induced nausea and vomiting have also been validated. ${ }^{140,141}$ Thus, several features of cannabinoid pharmacology are particularly desirable for an analgesic intervention aimed at managing neuropathic pain in AIDS and cancer patients.

\section{MS-induced neuropathic pain}

Several cannabinoid-based medicines have been evaluated in patients suffering from MS-related neuropathic pain. Cannabinoid-based medications have more frequently been evaluated for efficacy in suppressing MSrelated spasticity. ${ }^{142}$ Dronabinol reduced spontaneous pain intensity as measured with a numerical rating scale (NRS) for a 3-week treatment period, ${ }^{134}$ and improved overall pain ratings on the category rating scale for a 15-week treatment period. ${ }^{143}$ In addition, this drug improved median radiating pain intensity and pressure threshold, ${ }^{134}$ sleep quality, spasms, and spasticity ${ }^{143}$ in MS patients. Cannador is a medicinal cannabis preparation containing $\Delta^{9}$-THC and CBD in a $2: 1$ ratio. CBD is a natural constituent in cannabis, which has very low affinity for cannabinoid $\mathrm{CB}_{1}$ and $\mathrm{CB}_{2}$ receptors. It may act as a high potency antagonist of cannabinoid agonists and an inverse agonist at $\mathrm{CB}_{2}$ receptors. ${ }^{144} \mathrm{CBD}$ may compete with cannabinoid agonists for cannabinoid receptor binding sites, thereby minimizing psychoactivity of drugs that use a combination of $\Delta^{9}$-THC and CBD. The antinociceptive effects of CBD have also been attributed to inhibition of anandamide degradation, the antioxidant properties of the compound, or binding to an unknown cannabinoid receptor. ${ }^{144}$ CBD also acts as an agonist at serotonin 5-HT1a receptors. ${ }^{144}$ Cannador, ad- 
Table 7. Effects of Cannabinoids on Disease-Related Neuropathic Pain in Clinical Studies

\begin{tabular}{|c|c|c|c|c|c|}
\hline & Compound/Route & Primary Outcome Measure & Stimulus Evoked Pain & Secondary Outcome Measures & Ref No. \\
\hline \multirow[t]{2}{*}{ HIV-SN } & $\begin{array}{l}\text { Cannabis cigarettes } \\
\left(3.56 \% \Delta^{9}-\mathrm{THC}\right)^{*} \\
\text { Smoking }\end{array}$ & $\begin{array}{l}\text { VAS daily pain ratings }-52 \% \\
\text { reported }>30 \% \text { reduction } \\
\text { in pain }\end{array}$ & \multirow{2}{*}{$\begin{array}{l}\text { LTS - No effect; Heat and capasaicin } \\
\text { sensitization model - Reduced area } \\
\text { sensitive to mechanical allodynia }\end{array}$} & POMS - No effect & 135 \\
\hline & $\begin{array}{l}\text { Cannabis cigarettes } \\
\left(1-8 \% \Delta^{9}-\mathrm{THC}\right)^{\dagger} \\
\text { Smoking }\end{array}$ & $\begin{array}{l}\text { DDS and VAS pain ratings - } \\
46 \% \text { reported } \geq 30 \% \\
\text { reduction in pain }\end{array}$ & & $\begin{array}{l}\text { POMS/SIP/BSI/plasma VL and CD4+ } \\
\text { lymphocyte counts - No effect }\end{array}$ & 137 \\
\hline \multirow[t]{5}{*}{$\begin{array}{l}\text { Multiple } \\
\text { Sclerosis-related } \\
\text { Neuropathic } \\
\text { Pain }\end{array}$} & $\begin{array}{l}\text { Dronabinol } \\
\quad(\text { Marinol })^{\dagger} \text { p.o. }\end{array}$ & $\begin{array}{l}\text { NRS of median spontaneous } \\
\text { pain intensity - Reduction } \\
\text { from BL on this measure } \\
\text { was } 20.5 \%(-0.6 \text { pt.) with } \\
\text { Dronabinol vs. placebo }\end{array}$ & $\begin{array}{l}\text { Median radiating pain intensity/pressure } \\
\text { pain threshold - Improved; Cold and } \\
\text { warm sensibility/tactile detection/ } \\
\text { tactile pain detection/vibration sense/ } \\
\text { temporal summation/mechanical or } \\
\text { cold allodynia - No effect }\end{array}$ & $\begin{array}{l}\text { SF-36 - Improvements in bodily pain } \\
\text { and mental health categories }\end{array}$ & 134 \\
\hline & \multirow[t]{2}{*}{$\begin{array}{l}\text { Sativex }{ }^{*}, \text { Oral- } \\
\text { Mucosal Spray }\end{array}$} & $\begin{array}{l}\text { *NRS- } 11 \text { (pain) }--1.25 \mathrm{pt} \\
\text { reduction in favor of } \\
\text { Sativex }\end{array}$ & - & $\begin{array}{l}\text { NPS/NRS-11 Pain-related sleep } \\
\text { disturbances - Improved } \\
\text { PGIC - Sativex treated } 3.9 \times \text { more } \\
\text { likely than placebo to rate } \\
\text { themselves in an improved category } \\
\text { HADS/MS-related disability scale - } \\
\text { No effect }\end{array}$ & 146 \\
\hline & & $\begin{array}{l}\text { NRS-11 (pain) - No changes } \\
\text { in pain scores from } \\
\text { randomized 5-wk trial (up } \\
\text { to } 2 \text { y) - Sativex still } \\
\text { suppressing pain vs. BL }\end{array}$ & - & $\begin{array}{l}44 \% \text { of patients completed approximately } \\
2 \text { years of open-label study. } \\
\text { No increase in titration of dose }-N o \\
\text { tolerance }\end{array}$ & 147 \\
\hline & $\begin{array}{l}\text { Dronabinol } \\
\quad(\text { Marinol })^{\S} \text { p.o. } \\
\text { Cannador } \\
\text { C.o. }\end{array}$ & $\begin{array}{l}\text { Ashworth spasticity score - } \\
\text { No effect }\end{array}$ & - & $\begin{array}{l}\text { Category-rating scales - Improved } \\
\text { pain, sleep quality, spasms and } \\
\text { spasticity with CBM } \\
10 \mathrm{~m} \text { walk - Improved with CBM } \\
\text { Rivermead Mobility Index/Barthel } \\
\text { Index/GHQ-30/UKNDS - No effect }\end{array}$ & 143 \\
\hline & $\begin{array}{l}\text { Dronabinol } \\
\quad(\text { Marinol })^{\mathbb{I}} \text { p.o. } \\
\text { Cannador }^{\mathbb{I}} \text { p.o. }\end{array}$ & $\begin{array}{l}\text { Ashworth spasticity score - } \\
\text { Improvement after } \\
\text { dronabinol }\end{array}$ & - & $\begin{array}{l}\text { Category rating scales - Improved } \\
\text { pain, spasms, spasticity, sleep, } \\
\text { shakiness, energy level and } \\
\text { tiredness with CBM } \\
\text { Rivermead Mobility Index/Barthel } \\
\text { Index/GHQ-30/UKNDS/10 m } \\
\text { walk - No effect }\end{array}$ & 145 \\
\hline
\end{tabular}

$\mathrm{BL}=$ baseline; $\mathrm{BSI}=$ brief symptom inventory; $\mathrm{CBM}=$ cannabinoid-based medicine; DDS $=$ descriptor differential scale; GHQ $=$ general health questionnaire; HADS = hospital anxiety and depression scale; HIV-SN = HIV-associated sensory neuropathy; LTS = long-term thermal stimulation; MS = multiple sclerosis; NPS = neuropathic pain scale; NRS = numerical rating scale; PGIC $=$ patient global impression of change; p.o. = per orem; pt. = point; POMS = profile of mood states; SF- $36=$ short form health questionnaire; SIP $=$ sickness impact profile; THC $=$ tetrahydrocannabinol; UKNDS $=$ United Kingdom neurological disability score; VAS $=$ visual analogue scale; VL $=$ viral load

*Double-blind, placebo-controlled; ${ }^{\dagger}$ double-blind, placebo-controlled crossover; ${ }^{\ddagger}$ open label extension of randomized, double-blind, placebo-controlled study; ${ }^{\S}$ randomized, placebo-controlled;

Idouble-blind, placebo-controlled 1-year extension. 
Table 8. Effects of Cannabinoids in Injury-Related and Mixed Neuropathic Pain in Clinical Studies

\begin{tabular}{ccc}
\hline & Compound/Route & Primary Outcome Measure \\
\hline Brachial Plexus & Sativex $/ \Delta^{9}-\mathrm{THC}^{*}$ Oral & BS-11 (pain) - Sativex reduced pain by \\
Avulsion & Mucosal Spray & 0.58 boxes vs. placebo \\
& & $\Delta^{9}-$ THC reduced pain by 0.64 boxes vs. \\
& & placebo
\end{tabular}

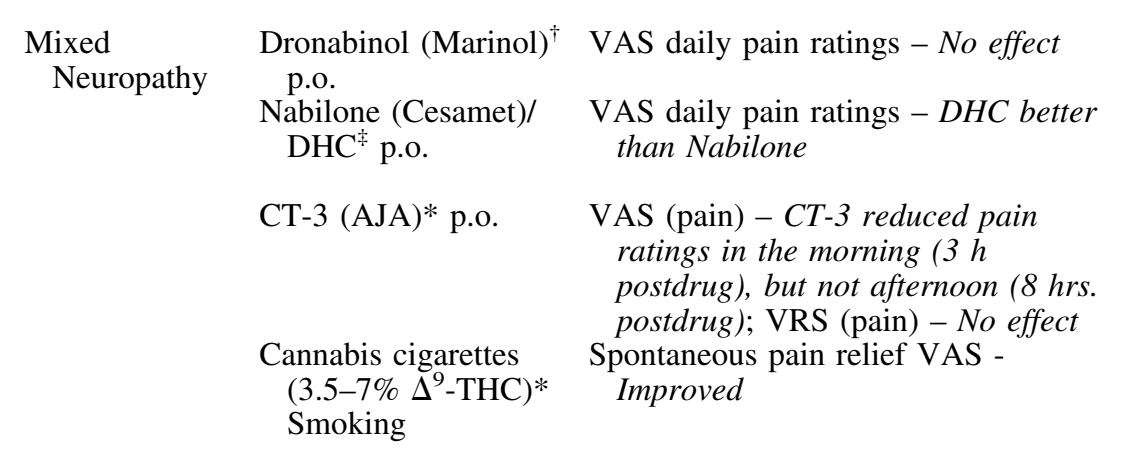
$\Delta^{9}$-THC/CBD/Sativex* VAS of 2 worst symptoms - Decrease Oral-Mucosal Spray in symptoms following $\Delta^{9}-$ THC and (Open-label phase Sativex relative to placebo

with Sativex prior

to crossover) placebo
Brush-induced mechanical allodynia No effect

Stimulus Evoked Pain
Decrease in mechanical hypersensitivity (von Frey) in group receiving AJA prior to placebo $(p=0.052)$

Mechanical allodynia (foam brush) VAS; Thermal hyperalgesis VAS No effect

VAS daily ratings of target symptoms $C B D$ and $\Delta^{9}-$ THC improved pain;

$\Delta^{9}-$ THC and Sativex improved

spasms; $\Delta^{9}$-THC improved spasticity
Secondary Outcome Measures Ref No.

Pain review BS-11/Sleep quality 150

BS-11/Sleep disturbances -

Improved with CBM

GHQ-12 - Improved with Sativex

SF-MPQ Pain rating index and VAS - Improved with $\Delta^{9}$. THC

PDI - No Effect

MPQ/BPI/HADS/Notingham health profile - No effect

SF-36 - Physical role improved 166 with nabilone; Bodily pain improved with $\mathrm{DHC}$

TMT; ARCI-M - No effect

Pain Unpleasantness

VAS/NPS - Improved

Degree of pain relief

PGIC/Psychoactive effects/

Neurocognitive effects -

Greater with cannabis; Mood

VAS - No effect

Quality of sleep - Improved with all $C B M$

Duration of sleep - No effect

BDI/GHQ-28-Qualitative

improvement in mood

following CBM

Numerical symptom scale -

Spasticity severity improved

with all CBM; frequency of muscle spasms improved with $\Delta^{9}-$ THC and Sativex

VAS daily ratings $-\Delta^{9}-T H C$

improved appetite; Sativex

improved sleep 


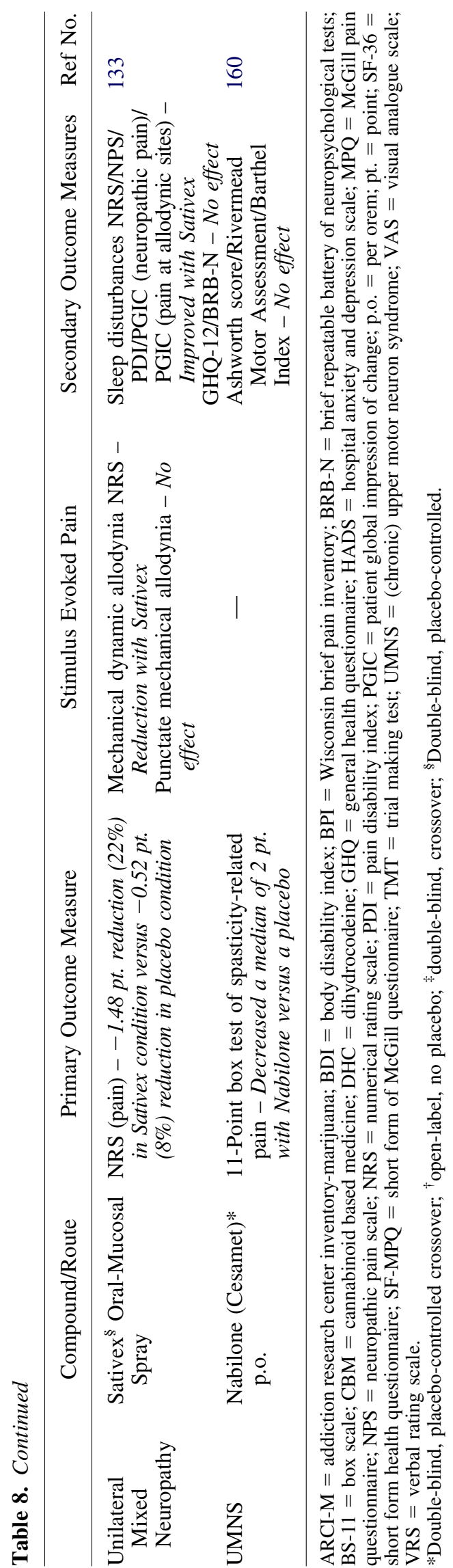

ministered for a 15-week treatment period, improved overall pain ratings, as well as sleep quality, spasms, and spasticity on category rating scales in patients suffering from MS-related neuropathic pain. ${ }^{143}$ A 1-year, doubleblind, placebo-controlled follow-up study in MS patients demonstrated improved symptoms of pain, spasms, spasticity, sleep, shakiness, energy level, and tiredness after administration of either dronabinol or Cannador. ${ }^{145}$ This study reported that $74 \%$ of the patients in the placebo group, versus $45 \%$ of the patients receiving cannabinoidbased medications, cited a lack of benefit derived from experimental medication as the reason for discontinuation of the trial. ${ }^{145} \mathrm{MS}$ patients receiving Sativex (a medicinal cannabis extract containing approximately a 1:1 ratio of CBD: $\Delta^{9}-\mathrm{THC}$, administered as an oral-mucosal spray) reported significant reductions in pain symptoms, as measured with the NRS-11 and neuropathic pain scale in a 4-week treatment period, double-blind, placebocontrolled study. ${ }^{146}$ Ninety-five percent of the patients in the placebo-controlled study chose to enter a 2-year open-label study with Sativex. ${ }^{147}$ Fifty-four percent of the patients completed 1 year and $44 \%$ of the patients completed 2 years of the study. Twenty-five percent withdrew due to adverse events, and 95\% experienced one or more adverse events during the course of treatment. The NRS-11, completed at the end of the trial, or upon withdrawal, was not different from the earlier randomized study indicating that Sativex was still suppressing pain. In addition, patients did not increase the titration of their dose indicating that no tolerance developed to Sativex. Most doses of Sativex were administered between $6 \mathrm{PM}$ and $12 \mathrm{AM}$, demonstrating that pain symptoms may be at their worst during normal sleeping hours for MS patients. A recent meta-analysis examining six studies of cannabinoid-based medications used for the treatment of MS-related neuropathic pain revealed that cannabis preparations were superior to a placebo. ${ }^{148}$

Increased $\mathrm{CB}_{2}$ immunoreactivity has been reported in spinal cords derived from MS patients. ${ }^{149}$ Here, greater numbers of microglia/macrophage cells expressing $\mathrm{CB}_{2}$ immunoreactivity were observed relative to controls. ${ }^{149}$ Thus, cannabinoid-based pharmacotherapies consistently show efficacy for suppressing pain due to MS, a disease state associated with an upregulation of $\mathrm{CB}_{2}$ receptors in microglia.

\section{Brachial plexus avulsion-induced neuropathy}

A single study has examined patients with neuropathic pain resulting exclusively from a brachial plexus avulsion (Table 8). This study ${ }^{150}$ used a 3-period crossover design with patients self-administering $\Delta^{9}$-THC, Sativex, or a placebo for 14 to 20 days per drug. Both $\Delta^{9}$-THC and Sativex reduced the primary outcome measure (boxscale 11 ordinal rating scale) in patients suffering from brachial plexus avulsion, indicating a reduction in pain 
symptoms versus placebo. Sleep quality disturbance scores were improved in patients receiving either active drug versus placebo. Eighty percent of the patients chose to enter an open-label study with Sativex after completion of this randomized study.

$\mathrm{CB}_{2}$ receptor immunoreactivity has been reported in normal and injured human DRG neurons, brachial plexus nerves, and neuromas, as well as peripheral nerve fibers. ${ }^{151}$ However, upregulation of $\mathrm{CB}_{2}$ receptor immunoreactivity was specifically observed in injured human nerve specimens and avulsed DRG obtained during surgery for brachial plexus repair. ${ }^{151}$ These observations correspond to preclinical observations of cannabinoid receptor upregulation after nerve injury. ${ }^{18}$ However, possible changes in $\mathrm{CB}_{1}$ receptor immunoreactivity were not evaluated in the human tissue, and therefore can not be excluded.

\section{Mixed neuropathic pain}

Recruitment of a patient population suffering from a specific form of neuropathic pain can be a difficult prospect; therefore, several studies include patients in which neuropathic pain is associated with different disease states or injuries (Table 8). A 21-patient study reported that ajulemic acid (CT-3) suppressed mixed forms of neuropathic pain, as assessed with the VAS, in the morning ( $3 \mathrm{~h}$ after drug administration), but not in the afternoon ( $8 \mathrm{~h}$ after drug administration). ${ }^{152}$ Eighteen of those same patients participated in stimulus-evoked pain testing during the study, and those patients showed a trend toward decreased mechanical allodynia after CT-3 administration. ${ }^{153} \mathrm{CT}-3$ binds with high affinity to both $\mathrm{CB}_{1}$ and $\mathrm{CB}_{2}$ receptors, and also binds with low affinity to PPAR $\gamma$ receptors. ${ }^{154} \mathrm{CT}-3$ has limited CNS availability, ${ }^{69}$ which translates into fewer $\mathrm{CB}_{1}$-mediated sideeffects.

Smoking cannabis cigarettes also improved spontaneous pain relief and pain unpleasantness VAS ratings in patients suffering from mixed forms of neuropathic pain, but failed to alter stimulus-evoked pain. ${ }^{155}$ This study reported that cannabinoids compounded the decreased neurocognitive performance of patients that was present at baseline. Using an " $\mathrm{N}$ of 1" preparation, Notcutt et al. ${ }^{156}$ determined if patients experienced improvements in pain after a 2-week open-label phase with Sativex prior to initiation of the double-blind, placebo-controlled crossover phase of the study. $\Delta^{9}$-THC and Sativex, but not placebo or CBD, reduced the VAS rating of the two worst pain symptoms during the crossover phase. ${ }^{156}$ Quality of sleep was improved by all cannabinoid-based medications ${ }^{156}$ and therefore may contribute to the therapeutic potential of the cannabinoids. By contrast, opioid analgesics produce deleterious effects on sleep architecture, including reductions in slow wave sleep and promotion of sleep apnea. ${ }^{157,158}$ A similarly structured study reported improved pain ratings (VAS) and spasticity severity after CBD and $\Delta^{9}$-THC in patients with mixed neuropathic pain. ${ }^{159} \Delta^{9}$-THC and Sativex also improved muscle spasms and spasticity severity. ${ }^{159}$

Sativex improved pain ratings as measured with the NRS in a 5-week, double-blind, placebo-controlled study performed in patients experiencing unilateral neuropathic pain. ${ }^{133}$ In this study, Sativex reduced mechanical dynamic and punctate allodynia, and improved sleep disturbances. ${ }^{133}$ Seventy-one percent of the patients tested chose to continue to the open-label study of Sativex with $63 \%$ withdrawing by the end of the study for various reasons. Nabilone (Cesamet) decreased measures of spasticity-related pain (11-point box test) in patients experiencing chronic upper motor neuron syndrome associated with a number of pain syndromes. ${ }^{160}$ In a retrospective review of patient charts at the Pain Center of the McGill University Health Center from 1999 to $2003,{ }^{161}$ $75 \%$ of patients received some benefit from taking Nabilone (whether it came in the form of pain relief, improved sleep, decreased nausea, or increased appetite).

Two studies have examined the effects of cannabinoidbased medications in patients suffering from spinal cord injuries. An early case study reported pain relief and improvement in spasticity in a patient with a spinal cord injury after oral $\Delta^{9}$-THC. ${ }^{162}$ A later study reported that $18 \%$ of the patients with spinal cord injuries reported pain relief after treatment with oral dronabinol (mean, 31 mg per day), whereas $23 \%$ experienced enhancement of pain resulting in subsequent withdrawal by several patients. ${ }^{163}$ Changes in experimental design after initiation of the study complicate interpretation of these latter findings. ${ }^{163}$

\section{Caveats}

We are aware of only two clinical studies that have failed to report efficacy of cannabinoids, relative to placebo, for treatment of mixed neuropathic pain. ${ }^{164,165}$ Our analysis of the study by Clermont-Gnamien et al. ${ }^{165}$ is restricted to information provided in the abstract, published in English. Both of these studies used eight or fewer subjects and evaluated dronabinol titrated to a dose of $25 \mathrm{mg} / \mathrm{day}$ (where tolerated). The mean dose was $16.6 \pm 6.5 \mathrm{mg}$ oral dronabinol in one study ${ }^{164}$ and $15 \pm$ $6 \mathrm{mg}$ in the other study. ${ }^{165}$ The two studies associated with negative outcomes for cannabinoids in managing neuropathic pain shared several common features: 1) evaluation of mixed neuropathic pain syndromes known to be refractory to multiple analgesic treatments, 2) evaluation of orally-administered $\Delta^{9}$-THC (dronabinol) as opposed to mixtures of $\Delta^{9}$-THC and CBD, or smoked marijuana, 3) small numbers of subjects, and 4) observation of prominent side effects (e.g., sedation) resulting in high dropout rates. One study reported side effects that were more prominent in older patients and did not cor- 
relate with analgesia. ${ }^{164}$ Of course, one difficulty in evaluating efficacy of analgesics in patients with neuropathic pain refractory to all known treatments is that there is no indication that these patients would respond favorably to any analgesic under the study conditions. In a third study, effects of Nabilone were compared with dihydrocodeine in a randomized, crossover, double-blind study of 3-months duration that did not include a pharmacologically inert placebo condition. In this latter study, ${ }^{166}$ it was concluded that the weak opioid dihydrocodeine was a statistically better treatment for chronic neuropathic pain than Nabilone. ${ }^{166}$ Patients in this study exhibited a mean baseline VAS rating of $69.6 \mathrm{~mm}$ on a 0 to $100 \mathrm{~mm}$ VAS scale; mean VAS ratings were $59.93 \pm 24.42 \mathrm{~mm}$ and $58.58 \pm 24.08 \mathrm{~mm}$ for patients taking Nabilone and dihydrocodeine, respectively. However, the authors noted that a small number of subjects responded well to Nabilone, and side effects were generally mild and in the expected range. ${ }^{166}$ Benefits of an add-on treatment with Nabilone have nonetheless been noted in patients with chronic therapy-resistant pain (observed in a causal relationship with a pathological status of the skeletal and locomotor system). ${ }^{167}$ Oral dronabinol produced significant pain relief versus placebo when combined with opioid therapy in both a double-blind, placebo-controlled crossover phase and a subsequent open-label extension. ${ }^{168}$ Patients also reported improvements in sleep problems and disturbances while experiencing an increase in sleep adequacy in the open-label phase of the study. ${ }^{168}$ Thus, caution should be exerted prior to concluding that side effects of cannabinoids seriously limit the therapeutic potential of cannabinoid pharmacotherapies for pain. Combination therapies, including a cannabinoid and opioid analgesic, show efficacy for treatmentresistant neuropathic pain and may be used to limit doses of analgesics or adjuvants associated with adverse side effects.

\section{Side effects}

Diverse neuropathic pain states (characterized as idiopathic, diabetic, immune-mediated, cobalamin-deficiency related, monoclonal gammopathy-related, alcohol abuse-related, and other) were recently examined in a prospective evaluation of specific chronic polyneuropathy syndromes and their response to pharmacological therapies. ${ }^{169}$ Intolerable side effects were observed in all groups of patients receiving either gabapentainoids, tricyclic antidepressants, anticonvulsants, cannabinoids (Nabilone or Sativex), or topical agents. ${ }^{169}$ Notably, the presence of intolerable side effects was similar among the different classes of medications. ${ }^{169}$ In this study, most forms of neuropathic pain had similar prevalence rates and responsiveness to the different pharmacotherapies evaluated. ${ }^{169}$
A recent systematic review of adverse effects of medical cannabinoids concluded that most adverse events $(96.6 \%)$ were not serious and no serious adverse events were related exclusively to cannabinoid administration. Moreover, $99 \%$ of serious adverse events from randomized clinical trials were reported in only two trials. ${ }^{170}$ Greater numbers of nonserious adverse events were observed after cannabinoid treatment, as expected. ${ }^{170}$ Side effects were equally associated with the different cannabinoid pharmacotherapies; the average rate of nonserious adverse events was higher in patients receiving Sativex or oral $\Delta^{9}$-THC than controls. ${ }^{170}$ Thus, the main burden for the clinician is to balance therapeutic efficacy with the risk of intolerable side effects in the specific patient. ${ }^{169}$ High-quality trials of long-term exposure to cannabinoids-based medications, together with careful monitoring of patients, are required to better characterize safety issues related to the use of medical cannabinoids. ${ }^{170}$

\section{CONCLUSIONS}

Cannabis has been used for pain relief for centuries, although the mechanism underlying their analgesic effects was poorly understood until the discovery of cannabinoid receptors, and their endogenous ligands in the 1990s. During the last two decades, a large number of research articles have demonstrated the efficacy of cannabinoids and modulators of the endocannabinoid system in suppressing neuropathic pain in animal models. Cannabinoids suppress hyperalgesia and allodynia (i.e., mechanical allodynia, mechanical hyperalgesia, thermal hyperalgesia, and cold allodynia where evaluated), induced by diverse neuropathic pain states through $\mathrm{CB}_{1}$ and $\mathrm{CB}_{2}$ specific mechanisms. These studies have elucidated neuronal as well as nonneuronal sites (i.e., activated microglia) of action for cannabinoids in suppressing pathological pain states and documented regulatory changes in cannabinoid receptors and endocannabinoid accumulation in response to peripheral or central nervous system injury. Clinical studies largely reaffirm that cannabinoids show efficacy in suppressing diverse neuropathic pain states in humans. The psychoactive effects of centrally-acting cannabinoid agonists, nonetheless, represent a challenge for pain pharmacotherapies that directly activate $\mathrm{CB}_{1}$ receptors in the brain. However, nonserious adverse events (e.g., dizziness), which pose the major limitation to patient compliance with pharmacotherapy, are not unique to cannabinoids. Approaches that serve to minimize unwanted CNS side effects (e.g., by combining $\Delta^{9}$-THC with $\mathrm{CBD}$, or by targeting $\mathrm{CB}_{2}$ receptors, peripheral $\mathrm{CB}_{1}$ receptors, or the endocannabinoid system) represent an important direction for future research and clinical evaluation. The present review suggests that cannabinoids show promise for treatment of 
neuropathic pain in humans either alone or as an add-on to other therapeutic agents. Therefore, further evaluations of safety profiles associated with long-term effects of cannabinoids are warranted.

Acknowledgements: This work was supported by grants no. DA021644 and grant no. DA022478 (AGH). E.J.R. is supported by an APS and a Psi Chi Graduate Research Grant.

\section{REFERENCES}

1. Gaoni Y, Mechoulam R. Isolation, structure and partial synthesis of an active constituent of hashish. J Am Chem Soc 1964;86: 1946-1947.

2. Matsuda LA, Lolait SJ, Brownstein MJ, Young AC, Bonner TI. Structure of a cannabinoid receptor and functional expression of the cloned cDNA. Nature 1990;346:561-564.

3. Munro S, Thomas KL, Abu-Shaar M. Molecular characterization of a peripheral receptor for cannabinoids. Nature 1993; 365:61-65.

4. Guindon J, Hohmann AG. Cannabinoid CB2 receptors: a therapeutic target for the treatment of inflammatory and neuropathic pain. Br J Pharmacol 2008;153:319-334.

5. Ledent C, Valverde O, Cossu G, et al. Unresponsiveness to cannabinoids and reduced addictive effects of opiates in CB1 receptor knockout mice. Science 1999;283:401-404.

6. Buckley NE, McCoy KL, Mezey E, et al. Immunomodulation by cannabinoids is absent in mice deficient for the cannabinoid CB(2) receptor. Eur J Pharmacol 2000;396:141-149.

7. Agarwal N, Pacher P, Tegeder I, et al. Cannabinoids mediate analgesia largely via peripheral type 1 cannabinoid receptors in nociceptors. Nat Neurosci 2007;10:870-879.

8. Herkenham M, Lynn AB, Johnson MR, Melvin LS, de Costa BR, Rice KC. Characterization and localization of cannabinoid receptors in rat brain: a quantitative in vitro autoradiographic study. J Neurosci 1991;11:563-583.

9. Matsuda LA, Bonner TI, Lolait SJ. Localization of cannabinoid receptor mRNA in rat brain. J Comp Neurol 1993;327:535-550.

10. Hohmann AG, Herkenham M. Localization of central cannabinoid CB1 receptor messenger RNA in neuronal subpopulations of rat dorsal root ganglia: a double-label in situ hybridization study. Neuroscience 1999;90:923-931.

11. Malan TP Jr., Ibrahim MM, Deng H, et al. CB2 cannabinoid receptor-mediated peripheral antinociception. Pain 2001;93:239245.

12. Facci L, Dal Toso R, Romanello S, Buriani A, Skaper SD, Leon A. Mast cells express a peripheral cannabinoid receptor with differential sensitivity to anandamide and palmitoylethanolamide. Proc Natl Acad Sci U S A 1995;92:3376-3380.

13. Ross RA, Coutts AA, McFarlane SM, et al. Actions of cannabinoid receptor ligands on rat cultured sensory neurones: implications for antinociception. Neuropharmacology 2001;40:221-232.

14. Van Sickle MD, Duncan M, Kingsley PJ, et al. Identification and functional characterization of brainstem cannabinoid CB2 receptors. Science 2005;310:329-332.

15. Gong JP, Onaivi ES, Ishiguro $\mathrm{H}$, et al. Cannabinoid CB2 receptors: immunohistochemical localization in rat brain. Brain Res 2006;1071:10-23.

16. Ashton JC, Friberg D, Darlington CL, Smith PF. Expression of the cannabinoid CB2 receptor in the rat cerebellum: an immunohistochemical study. Neurosci Lett 2006;396:113-116.

17. Beltramo M, Bernardini N, Bertorelli R, et al. CB2 receptormediated antihyperalgesia: possible direct involvement of neural mechanisms. Eur J Neurosci 2006;23:1530-1538.

18. Wotherspoon G, Fox A, McIntyre P, Colley S, Bevan S, Winter J. Peripheral nerve injury induces cannabinoid receptor 2 protein expression in rat sensory neurons. Neuroscience 2005;135:235245.

19. Devane WA, Hanus L, Breuer A, et al. Isolation and structure of a brain constituent that binds to the cannabinoid receptor. Science 1992;258:1946-1949.
20. Mechoulam R, Ben-Shabat S, Hanus L, et al. Identification of an endogenous 2-monoglyceride, present in canine gut, that binds to cannabinoid receptors. Biochem Pharmacol 1995;50:83-90.

21. Sugiura T, Kondo S, Sukagawa A, et al. 2-Arachidonoylglycerol: a possible endogenous cannabinoid receptor ligand in brain. Biochem Biophys Res Commun 1995;215:89-97.

22. Hanus L, Abu-Lafi S, Fride E, et al. 2-arachidonyl glyceryl ether, an endogenous agonist of the cannabinoid CB1 receptor. Proc Natl Acad Sci U S A 2001;98:3662-3665.

23. Porter AC, Sauer JM, Knierman MD, et al. Characterization of a novel endocannabinoid, virodhamine, with antagonist activity at the CB1 receptor. J Pharmacol Exp Ther 2002;301:1020-1024.

24. Huang SM, Bisogno T, Trevisani M, et al. An endogenous capsaicin-like substance with high potency at recombinant and native vanilloid VR1 receptors. Proc Natl Acad Sci U S A 2002;99: 8400-8405.

25. Fezza F, De Simone C, Amadio D, Maccarrone M. Fatty acid amide hydrolase: a gate-keeper of the endocannabinoid system. Subcell Biochem 2008;49:101-132.

26. Lo Verme J, Fu J, Astarita G, et al. The nuclear receptor peroxisome proliferator-activated receptor-alpha mediates the anti-inflammatory actions of palmitoylethanolamide. Mol Pharmacol 2005;67:15-19.

27. Re G, Barbero R, Miolo A, Di Marzo V. Palmitoylethanolamide, endocannabinoids and related cannabimimetic compounds in protection against tissue inflammation and pain: potential use in companion animals. Vet J 2007;173:21-30.

28. Bisogno T, De Petrocellis L, Di Marzo V. Fatty acid amide hydrolase, an enzyme with many bioactive substrates. Possible therapeutic implications. Curr Pharm Des 2002;8:533-547.

29. Cravatt BF, Demarest K, Patricelli MP, et al. Supersensitivity to anandamide and enhanced endogenous cannabinoid signaling in mice lacking fatty acid amide hydrolase. Proc Natl Acad Sci U S A 2001;98:9371-9376.

30. Lichtman AH, Shelton CC, Advani T, Cravatt BF. Mice lacking fatty acid amide hydrolase exhibit a cannabinoid receptor-mediated phenotypic hypoalgesia. Pain 2004;109:319-327.

31. Ross RA, Gibson TM, Brockie HC, et al. Structure-activity relationship for the endogenous cannabinoid, anandamide, and certain of its analogues at vanilloid receptors in transfected cells and vas deferens. Br J Pharmacol 2001;132:631-640.

32. Bouaboula M, Hilairet S, Marchand J, Fajas L, Le Fur G, Casellas P. Anandamide induced PPARgamma transcriptional activation and 3T3-L1 preadipocyte differentiation. Eur J Pharmacol 2005; 517:174-181.

33. Hohmann AG, Suplita RL, Bolton NM, et al. An endocannabinoid mechanism for stress-induced analgesia. Nature 2005;435: $1108-1112$

34. Dinh TP, Carpenter D, Leslie FM, et al. Brain monoglyceride lipase participating in endocannabinoid inactivation. Proc Natl Acad Sci U S A 2002;99:10819-10824.

35. Dixon WE. The pharmacology of Cannabis indica. BMJ 1899;2: 1354-1357.

36. Walker JM, Hohmann AG. Cannabinoid mechanisms of pain suppression. Handb Exp Pharmacol 2005:509-554.

37. Bennett GJ, Xie YK. A peripheral mononeuropathy in rat that produces disorders of pain sensation like those seen in man. Pain 1988;33:87-107.

38. Lim G, Sung B, Ji RR, Mao J. Upregulation of spinal cannabinoid-1-receptors following nerve injury enhances the effects of Win 55,212-2 on neuropathic pain behaviors in rats. Pain 2003; 105:275-283.

39. Wang S, Lim G, Mao J, Sung B, Yang L, Mao J. Central glucocorticoid receptors regulate the upregulation of spinal cannabinoid-1 receptors after peripheral nerve injury in rats. Pain 2007; 131:96-105.

40. Costa B, Trovato AE, Comelli F, Giagnoni G, Colleoni M. The non-psychoactive cannabis constituent cannabidiol is an orally effective therapeutic agent in rat chronic inflammatory and neuropathic pain. Eur J Pharmacol 2007;556:75-83.

41. Comelli F, Giagnoni G, Bettoni I, Colleoni M, Costa B. Antihyperalgesic effect of a Cannabis sativa extract in a rat model of 
neuropathic pain: mechanisms involved. Phytother Res 2008;22:1017-1024.

42. Herzberg U, Eliav E, Bennett GJ, Kopin IJ. The analgesic effects of $\mathrm{R}(+)$-WIN 55,212-2 mesylate, a high affinity cannabinoid agonist, in a rat model of neuropathic pain. Neurosci Lett 1997; 221:157-160.

43. Costa B, Trovato AE, Colleoni M, Giagnoni G, Zarini E, Croci T. Effect of the cannabinoid CB1 receptor antagonist, SR141716, on nociceptive response and nerve demyelination in rodents with chronic constriction injury of the sciatic nerve. Pain 2005;116: $52-61$.

44. Ibrahim MM, Deng H, Zvonok A, et al. Activation of CB2 cannabinoid receptors by AM1241 inhibits experimental neuropathic pain: pain inhibition by receptors not present in the CNS. Proc Natl Acad Sci U S A 2003;100:10529-10533.

45. Sain NM, Liang A, Kane SA, Urban MO. Antinociceptive effects of the non-selective cannabinoid receptor agonist CP 55,940 are absent in CB1 $(-/-)$ and not CB2 $(-/-)$ mice in models of acute and persistent pain. Neuropharmacology 2009;57:235-241.

46. Strangman NM, Walker JM. Cannabinoid WIN 55,212-2 inhibits the activity-dependent facilitation of spinal nociceptive responses. J Neurophysiol 1999;82:472-477.

47. Liu C, Walker JM. Effects of a cannabinoid agonist on spinal nociceptive neurons in a rodent model of neuropathic pain. J Neurophysiol 2006;96:2984-2994.

48. Costa B, Colleoni M, Conti S, et al. Repeated treatment with the synthetic cannabinoid WIN 55,212-2 reduces both hyperalgesia and production of pronociceptive mediators in a rat model of neuropathic pain. Br J Pharmacol 2004;141:4-8.

49. Zhang J, Hoffert C, Vu HK, Groblewski T, Ahmad S, O’Donnell D. Induction of $\mathrm{CB} 2$ receptor expression in the rat spinal cord of neuropathic but not inflammatory chronic pain models. Eur J Neurosci 2003;17:2750-2754.

50. Hu B, Doods H, Treede RD, Ceci A. Depression-like behaviour in rats with mononeuropathy is reduced by the $\mathrm{CB} 2$-selective agonist GW405833. Pain 2009.

51. Yao BB, Hsieh G, Daza AV, et al. Characterization of a cannabinoid CB2 receptor-selective agonist, A-836339 [2,2,3,3-tetramethyl-cyclopropanecarboxylic acid [3-(2-methoxy-ethyl)-4,5-dimethyl-3Hthiazol-(2Z)-ylidene]-amide], using in vitro pharmacological assays, in vivo pain models, and pharmacological magnetic resonance imaging. J Pharmacol Exp Ther 2009;328:141-151.

52. Costa B, Siniscalco D, Trovato AE, et al. AM404, an inhibitor of anandamide uptake, prevents pain behaviour and modulates cytokine and apoptotic pathways in a rat model of neuropathic pain. Br J Pharmacol 2006;148:1022-1032.

53. La Rana G, Russo R, Campolongo P, et al. Modulation of neuropathic and inflammatory pain by the endocannabinoid transport inhibitor AM404 [N-(4-hydroxyphenyl)-eicosa-5,8,11,14-tetraenamide]. J Pharmacol Exp Ther 2006;317:1365-1371.

54. La Rana G, Russo R, D’Agostino G, et al. AM404, an anandamide transport inhibitor, reduces plasma extravasation in a model of neuropathic pain in rat: role for cannabinoid receptors. Neuropharmacology 2008;54:521-529.

55. Russo R, Loverme J, La Rana G, et al. The fatty acid amide hydrolase inhibitor URB597 (cyclohexylcarbamic acid 3'-carbamoylbiphenyl-3-yl ester) reduces neuropathic pain after oral administration in mice. J Pharmacol Exp Ther 2007;322:236242.

56. Petrosino S, Palazzo E, de Novellis V, et al. Changes in spinal and supraspinal endocannabinoid levels in neuropathic rats. Neuropharmacology 2007;52:415-422.

57. Palazzo E, de Novellis V, Petrosino S, et al. Neuropathic pain and the endocannabinoid system in the dorsal raphe: pharmacological treatment and interactions with the serotonergic system. Eur J Neurosci 2006;24:2011-2020.

58. Rodella LF, Borsani E, Rezzani R, Ricci F, Buffoli B, Bianchi R. AM404, an inhibitor of anandamide reuptake decreases Fos-immunoreactivity in the spinal cord of neuropathic rats after nonnoxious stimulation. Eur J Pharmacol 2005;508:139-146.

59. Kinsey SG, Long JZ, O'Neal ST, et al. Blockade of endocannabinoid-degrading enzymes attenuates neuropathic pain. J Pharmacol Exp Ther 2009.
60. Costa B, Comelli F, Bettoni I, Colleoni M, Giagnoni G. The endogenous fatty acid amide, palmitoylethanolamide, has antiallodynic and anti-hyperalgesic effects in a murine model of neuropathic pain: involvement of $\mathrm{CB}(1)$, TRPV1 and PPARgamma receptors and neurotrophic factors. Pain 2008.

61. Seltzer Z, Dubner R, Shir Y. A novel behavioral model of neuropathic pain disorders produced in rats by partial sciatic nerve injury. Pain 1990;43:205-218.

62. Jayamanne A, Greenwood R, Mitchell VA, Aslan S, Piomelli D, Vaughan CW. Actions of the FAAH inhibitor URB597 in neuropathic and inflammatory chronic pain models. Br J Pharmacol 2006; $147: 281-288$.

63. Racz I, Nadal X, Alferink J, et al. Crucial role of $\mathrm{CB}(2)$ cannabinoid receptor in the regulation of central immune responses during neuropathic pain. J Neurosci 2008;28:12125-12135.

64. Wallace VC, Segerdahl AR, Lambert DM, et al. The effect of the palmitoylethanolamide analogue, palmitoylallylamide (L-29) on pain behaviour in rodent models of neuropathy. Br J Pharmacol 2007;151:1117-1128.

65. Helyes Z, Nemeth J, Than M, Bolcskei K, Pinter E, Szolcsanyi J. Inhibitory effect of anandamide on resiniferatoxin-induced sensory neuropeptide release in vivo and neuropathic hyperalgesia in the rat. Life Sci 2003;73:2345-2353.

66. Guindon J, Beaulieu P. Antihyperalgesic effects of local injections of anandamide, ibuprofen, rofecoxib and their combinations in a model of neuropathic pain. Neuropharmacology 2006;50:814-823.

67. Desroches J, Guindon J, Lambert C, Beaulieu P. Modulation of the anti-nociceptive effects of 2-arachidonoyl glycerol by peripherally administered FAAH and MGL inhibitors in a neuropathic pain model. Br J Pharmacol 2008;155:913-924.

68. Fox A, Kesingland A, Gentry C, et al. The role of central and peripheral Cannabinoid 1 receptors in the antihyperalgesic activity of cannabinoids in a model of neuropathic pain. Pain 2001;92: 91-100.

69. Dyson A, Peacock M, Chen A, et al. Antihyperalgesic properties of the cannabinoid CT-3 in chronic neuropathic and inflammatory pain states in the rat. Pain 2005;116:129-137.

70. Yamamoto W, Mikami T, Iwamura H. Involvement of central cannabinoid $\mathrm{CB} 2$ receptor in reducing mechanical allodynia in a mouse model of neuropathic pain. Eur J Pharmacol 2008;583: $56-61$.

71. Racz I, Nadal X, Alferink J, et al. Interferon-gamma is a critical modulator of $\mathrm{CB}(2)$ cannabinoid receptor signaling during neuropathic pain. J Neurosci 2008;28:12136-12145.

72. Staton PC, Hatcher JP, Walker DJ, et al. The putative cannabinoid receptor GPR55 plays a role in mechanical hyperalgesia associated with inflammatory and neuropathic pain. Pain 2008;139: 225-236.

73. Mitchell VA, Greenwood R, Jayamanne A, Vaughan CW. Actions of the endocannabinoid transport inhibitor AM404 in neuropathic and inflammatory pain models. Clin Exp Pharmacol Physiol 2007:34:1186-1190.

74. Lambert DM, Di Marzo V. The palmitoylethanolamide and oleamide enigmas: are these two fatty acid amides cannabimimetic? Curr Med Chem 1999;6:757-773.

75. Vuong LA, Mitchell VA, Vaughan CW. Actions of N-arachidonyl-glycine in a rat neuropathic pain model. Neuropharmacology 2008;54:189-193.

76. Dani M, Guindon J, Lambert C, Beaulieu P. The local antinociceptive effects of paracetamol in neuropathic pain are mediated by cannabinoid receptors. Eur J Pharmacol 2007;573:214-215.

77. Kim SH, Chung JM. An experimental model for peripheral neuropathy produced by segmental spinal nerve ligation in the rat. Pain 1992;50:355-363.

78. De Vry J, Denzer D, Reissmueller E, et al. 3-[2-cyano-3-(trifluoromethyl)phenoxy]phenyl-4,4,4-trifluoro-1-butanesulfo nate (BAY 59-3074): a novel cannabinoid $\mathrm{Cb} 1 / \mathrm{Cb} 2$ receptor partial agonist with antihyperalgesic and antiallodynic effects. J Pharmacol Exp Ther 2004;310:620-632.

79. Bridges D, Ahmad K, Rice AS. The synthetic cannabinoid WIN55,212-2 attenuates hyperalgesia and allodynia in a rat model of neuropathic pain. Br J Pharmacol 2001;133:586-594.

80. LaBuda CJ, Little PJ. Pharmacological evaluation of the selective 
spinal nerve ligation model of neuropathic pain in the rat. J Neurosci Methods 2005;144:175-181.

81. Leichsenring A, Andriske M, Backer I, Stichel CC, Lubbert H. Analgesic and antiinflammatory effects of cannabinoid receptor agonists in a rat model of neuropathic pain. Naunyn Schmiedebergs Arch Pharmacol 2009;379:627-636.

82. Chapman V. Functional changes in the inhibitory effect of spinal cannabinoid $(\mathrm{CB})$ receptor activation in nerve injured rats. Neuropharmacology 2001;41:870-877.

83. Mitrirattanakul S, Ramakul N, Guerrero AV, et al. Site-specific increases in peripheral cannabinoid receptors and their endogenous ligands in a model of neuropathic pain. Pain 2006;126:102114.

84. Kawasaki Y, Kohno T, Ji RR. Different effects of opioid and cannabinoid receptor agonists on C-fiber-induced extracellular signal-regulated kinase activation in dorsal horn neurons in normal and spinal nerve-ligated rats. J Pharmacol Exp Ther 2006; 316:601-607.

85. Naguib M, Diaz P, Xu JJ, et al. MDA7: a novel selective agonist for $\mathrm{CB} 2$ receptors that prevents allodynia in rat neuropathic pain models. Br J Pharmacol 2008;155:1104-1116.

86. Elmes SJ, Jhaveri MD, Smart D, Kendall DA, Chapman V. Cannabinoid CB2 receptor activation inhibits mechanically evoked responses of wide dynamic range dorsal horn neurons in naive rats and in rat models of inflammatory and neuropathic pain. Eur J Neurosci 2004;20:2311-2320.

87. Jhaveri MD, Elmes SJ, Richardson D, et al. Evidence for a novel functional role of cannabinoid $\mathrm{CB}(2)$ receptors in the thalamus of neuropathic rats. Eur J Neurosci 2008;27:1722-1730.

88. McGaraughty S, Chu KL, Dart MJ, Yao BB, Meyer MD. A $\mathrm{CB}(2)$ receptor agonist, A-836339, modulates wide dynamic range neuronal activity in neuropathic rats: contributions of spinal and peripheral $\mathrm{CB}(2)$ receptors. Neuroscience 2009;158:16521661.

89. Rahn EJ, Zvonok AM, Thakur GA, Khanolkar AD, Makriyannis A, Hohmann AG. Selective activation of cannabinoid CB2 receptors suppresses neuropathic nociception induced by treatment with the chemotherapeutic agent paclitaxel in rats. J Pharmacol Exp Ther 2008;327:584-591.

90. Sit SY, Conway C, Bertekap R, et al. Novel inhibitors of fatty acid amide hydrolase. Bioorg Med Chem Lett 2007;17:32873291.

91. Chang L, Luo L, Palmer JA, et al. Inhibition of fatty acid amide hydrolase produces analgesia by multiple mechanisms. Br J Pharmacol 2006;148:102-113.

92. Jhaveri MD, Richardson D, Kendall DA, Barrett DA, Chapman $\mathrm{V}$. Analgesic effects of fatty acid amide hydrolase inhibition in a rat model of neuropathic pain. J Neurosci 2006;26:13318-13327.

93. Vos BP, Maciewicz R. Behavioral changes following ligation of the infraorbital nerve in rats: an animal model of trigeminal neuropathic pain. In: Besson JM, Guilbaud G, eds. Lesions of primary afferent fibers as a tool for the study of clinical pain. Amsterdam: Elsevier, 1991:147-158.

94. Liang YC, Huang CC, Hsu KS. The synthetic cannabinoids attenuate allodynia and hyperalgesia in a rat model of trigeminal neuropathic pain. Neuropharmacology 2007;53:169-177.

95. Liang YC, Huang CC, Hsu KS, Takahashi T. Cannabinoid-induced presynaptic inhibition at the primary afferent trigeminal synapse of juvenile rat brainstem slices. J Physiol 2004;555: $85-96$.

96. Romero-Sandoval A, Nutile-McMenemy N, DeLeo JA. Spinal microglial and perivascular cell cannabinoid receptor type 2 activation reduces behavioral hypersensitivity without tolerance after peripheral nerve injury. Anesthesiology 2008;108:722-734.

97. Tanga FY, Nutile-McMenemy N, DeLeo JA. The CNS role of Toll-like receptor 4 in innate neuroimmunity and painful neuropathy. Proc Natl Acad Sci U S A 2005;102:5856-5861.

98. Walczak JS, Pichette V, Leblond F, Desbiens K, Beaulieu P. Behavioral, pharmacological and molecular characterization of the saphenous nerve partial ligation: a new model of neuropathic pain. Neuroscience 2005;132:1093-1102.

99. Walczak JS, Pichette V, Leblond F, Desbiens K, Beaulieu P. Characterization of chronic constriction of the saphenous nerve, a model of neuropathic pain in mice showing rapid molecular and electrophysiological changes. J Neurosci Res 2006;83:13101322.

100. Decosterd I, Woolf CJ. Spared nerve injury: an animal model of persistent peripheral neuropathic pain. Pain 2000;87:149-158.

101. Decosterd I, Allchorne A, Woolf CJ. Differential analgesic sensitivity of two distinct neuropathic pain models. Anesth Analg 2004;99:457-463.

102. Bruce JC, Oatway MA, Weaver LC. Chronic pain after clipcompression injury of the rat spinal cord. Exp Neurol 2002;178: 33-48.

103. Hama A, Sagen J. Antinociceptive effect of cannabinoid agonist WIN 55,212-2 in rats with a spinal cord injury. Exp Neurol 2007;204:454-457.

104. Hama A, Sagen J. Sustained antinociceptive effect of cannabinoid receptor agonist WIN 55,212-2 over time in rat model of neuropathic spinal cord injury pain. J Rehabil Res Dev 2009;46:135143.

105. Hofmann HA, De Vry J, Siegling A, Spreyer P, Denzer D. Pharmacological sensitivity and gene expression analysis of the tibial nerve injury model of neuropathic pain. Eur J Pharmacol 2003; 470:17-25.

106. Siegling A, Hofmann HA, Denzer D, Mauler F, De Vry J. Cannabinoid $\mathrm{CB}(1)$ receptor upregulation in a rat model of chronic neuropathic pain. Eur J Pharmacol 2001;415:R5-7.

107. Bujalska M. Effect of cannabinoid receptor agonists on streptozotocin-induced hyperalgesia in diabetic neuropathy. Pharmacology 2008;82:193-200.

108. Zhang F, Hong S, Stone V, Smith PJ. Expression of cannabinoid CB1 receptors in models of diabetic neuropathy. J Pharmacol Exp Ther 2007;323:508-515.

109. Matias I, Wang JW, Moriello AS, Nieves A, Woodward DF, Di Marzo V. Changes in endocannabinoid and palmitoylethanolamide levels in eye tissues of patients with diabetic retinopathy and age-related macular degeneration. Prostaglandins Leukot Essent Fatty Acids 2006;75:413-418.

110. Engeli S, Bohnke J, Feldpausch M, et al. Activation of the peripheral endocannabinoid system in human obesity. Diabetes 2005;54:2838-2843.

111. Murdolo G, Kempf K, Hammarstedt A, Herder C, Smith U, Jansson PA. Insulin differentially modulates the peripheral endocannabinoid system in human subcutaneous abdominal adipose tissue from lean and obese individuals. J Endocrinol Invest 2007; 30:RC17-21.

112. Scheen AJ. The endocannabinoid system: a promising target for the management of type 2 diabetes. Curr Protein Pept Sci 2009; 10:56-74.

113. Watanabe T, Kubota N, Ohsugi M, et al. Rimonabant ameliorates insulin resistance via both adiponectin-dependent and adiponectin-independent pathways. J Biol Chem 2009;284: 1803-1812.

114. Dagon Y, Avraham Y, Link G, Zolotarev O, Mechoulam R, Berry EM. The synthetic cannabinoid HU-210 attenuates neural damage in diabetic mice and hyperglycemic pheochromocytoma PC12 cells. Neurobiol Dis 2007;27:174-181.

115. Williams J, Haller VL, Stevens DL, Welch SP. Decreased basal endogenous opioid levels in diabetic rodents: effects on morphine and delta-9-tetrahydrocannabinoid-induced antinociception. Eur J Pharmacol 2008;584:78-86.

116. Vera G, Chiarlone A, Cabezos PA, Pascual D, Martin MI, Abalo R. WIN 55,212-2 prevents mechanical allodynia but not alterations in feeding behaviour induced by chronic cisplatin in the rat. Life Sci 2007;81:468-479.

117. Ray AP, Griggs L, Darmani NA. Delta 9-tetrahydrocannabinol suppresses vomiting behavior and Fos expression in both acute and delayed phases of cisplatin-induced emesis in the least shrew. Behav Brain Res 2009;196:30-36.

118. Polomano RC, Mannes AJ, Clark US, Bennett GJ. A painful peripheral neuropathy in the rat produced by the chemotherapeutic drug, paclitaxel. Pain 2001;94:293-304.

119. Pascual D, Goicoechea C, Suardiaz M, Martin MI. A cannabinoid agonist, WIN 55,212-2, reduces neuropathic nociception induced by paclitaxel in rats. Pain 2005;118:23-34. 
120. Flatters SJ, Bennett GJ. Ethosuximide reverses paclitaxel- and vincristine-induced painful peripheral neuropathy. Pain 2004; 109:150-161.

121. Weng HR, Cordella JV, Dougherty PM. Changes in sensory processing in the spinal dorsal horn accompany vincristine-induced hyperalgesia and allodynia. Pain 2003;103:131-138.

122. Rahn EJ, Makriyannis A, Hohmann AG. Activation of cannabinoid $\mathrm{CB} 1$ and $\mathrm{CB} 2$ receptors suppresses neuropathic nociception evoked by the chemotherapeutic agent vincristine in rats. $\mathrm{Br} \mathrm{J}$ Pharmacol 2007;152:765-777.

123. Wallace VC, Blackbeard J, Segerdahl AR, et al. Characterization of rodent models of HIV-gp120 and anti-retroviral-associated neuropathic pain. Brain 2007;130:2688-2702.

124. Wallace VC, Blackbeard J, Pheby T, et al. Pharmacological, behavioural and mechanistic analysis of HIV-1 gp120 induced painful neuropathy. Pain 2007;133:47-63.

125. Wallace VC, Cottrell DF, Brophy PJ, Fleetwood-Walker SM. Focal lysolecithin-induced demyelination of peripheral afferents results in neuropathic pain behavior that is attenuated by cannabinoids. J Neurosci 2003;23:3221-3233.

126. Lynch JL, Gallus NJ, Ericson ME, Beitz AJ. Analysis of nociception, sex and peripheral nerve innervation in the TMEV animal model of multiple sclerosis. Pain 2008;136:293-304.

127. Buchanan RJ, Wang S, Ju H. Gender analyses of nursing home residents with multiple sclerosis. J Gend Specif Med 2003;6: $35-46$.

128. Olechowski CJ, Truong JJ, Kerr BJ. Neuropathic pain behaviours in a chronic-relapsing model of experimental autoimmune encephalomyelitis (EAE). Pain 2009;141:156-164.

129. Loria F, Petrosino S, Mestre L, et al. Study of the regulation of the endocannabinoid system in a virus model of multiple sclerosis reveals a therapeutic effect of palmitoylethanolamide. Eur J Neurosci 2008;28:633-641.

130. LoVerme J, Russo R, La Rana G, et al. Rapid broad-spectrum analgesia through activation of peroxisome proliferator-activated receptor-alpha. J Pharmacol Exp Ther 2006;319:10511061.

131. Hasnie FS, Breuer J, Parker S, et al. Further characterization of a rat model of varicella zoster virus-associated pain: Relationship between mechanical hypersensitivity and anxiety-related behavior, and the influence of analgesic drugs. Neuroscience 2007;144: 1495-1508.

132. Beaulieu P, Ware M. Reassessment of the role of cannabinoids in the management of pain. Curr Opin Anaesthesiol 2007;20:473477.

133. Nurmikko TJ, Serpell MG, Hoggart B, Toomey PJ, Morlion BJ, Haines D. Sativex successfully treats neuropathic pain characterised by allodynia: a randomised, double-blind, placebo-controlled clinical trial. Pain 2007;133:210-220.

134. Svendsen KB, Jensen TS, Bach FW. Does the cannabinoid dronabinol reduce central pain in multiple sclerosis? Randomised double blind placebo controlled crossover trial. BMJ 2004;329: 253.

135. Abrams DI, Jay CA, Shade SB, et al. Cannabis in painful HIVassociated sensory neuropathy: a randomized placebo-controlled trial. Neurology 2007;68:515-521.

136. Abrams DI, Hilton JF, Leiser RJ, et al. Short-term effects of cannabinoids in patients with HIV-1 infection: a randomized, placebo-controlled clinical trial. Ann Intern Med 2003;139:258266.

137. Ellis RJ, Toperoff W, Vaida F, et al. Smoked medicinal cannabis for neuropathic pain in HIV: a randomized, crossover clinical trial. Neuropsychopharmacology 2009;34:672-680.

138. Woolridge E, Barton S, Samuel J, Osorio J, Dougherty A, Holdcroft A. Cannabis use in HIV for pain and other medical symptoms. J Pain Symptom Manage 2005;29:358-367.

139. Beal JE, Olson R, Laubenstein L, et al. Dronabinol as a treatment for anorexia associated with weight loss in patients with AIDS. J Pain Symptom Manage 1995;10:89-97.

140. Vincent BJ, McQuiston DJ, Einhorn LH, Nagy CM, Brames MJ. Review of cannabinoids and their antiemetic effectiveness. Drugs 1983;25(suppl 1):52-62.

141. Tramer MR, Carroll D, Campbell FA, Reynolds DJ, Moore RA,
McQuay HJ. Cannabinoids for control of chemotherapy induced nausea and vomiting: quantitative systematic review. BMJ 2001;323:16-21.

142. Malfitano AM, Proto MC, Bifulco M. Cannabinoids in the management of spasticity associated with multiple sclerosis. Neuropsychiatr Dis Treat 2008;4:847-853.

143. Zajicek J, Fox P, Sanders H, et al. Cannabinoids for treatment of spasticity and other symptoms related to multiple sclerosis (CAMS study): multicentre randomised placebo-controlled trial. Lancet 2003;362:1517-1526.

144. Mechoulam R, Peters M, Murillo-Rodriguez E, Hanus LO. Cannabidiol-recent advances. Chem Biodivers 2007;4:1678-1692.

145. Zajicek JP, Sanders HP, Wright DE, et al. Cannabinoids in multiple sclerosis (CAMS) study: safety and efficacy data for 12 months follow up. J Neurol Neurosurg Psychiatry 2005;76:16641669.

146. Rog DJ, Nurmikko TJ, Friede T, Young CA. Randomized, controlled trial of cannabis-based medicine in central pain in multiple sclerosis. Neurology 2005;65:812-819.

147. Rog DJ, Nurmikko TJ, Young CA. Oromucosal delta9-tetrahydrocannabinol/cannabidiol for neuropathic pain associated with multiple sclerosis: an uncontrolled, open-label, 2-year extension trial. Clin Ther 2007;29:2068-2079.

148. Iskedjian M, Bereza B, Gordon A, Piwko C, Einarson TR. Metaanalysis of cannabis based treatments for neuropathic and multiple sclerosis-related pain. Curr Med Res Opin 2007;23:17-24.

149. Yiangou Y, Facer P, Durrenberger P, et al. COX-2, CB2 and $\mathrm{P} 2 \mathrm{X} 7$-immunoreactivities are increased in activated microglial cells/macrophages of multiple sclerosis and amyotrophic lateral sclerosis spinal cord. BMC Neurol 2006;6:12.

150. Berman JS, Symonds C, Birch R. Efficacy of two cannabis based medicinal extracts for relief of central neuropathic pain from brachial plexus avulsion: results of a randomised controlled trial. Pain 2004;112:299-306.

151. Anand U, Otto WR, Sanchez-Herrera D, et al. Cannabinoid receptor CB2 localisation and agonist-mediated inhibition of capsaicin responses in human sensory neurons. Pain 2008;138:667680 .

152. Karst M, Salim K, Burstein S, Conrad I, Hoy L, Schneider U. Analgesic effect of the synthetic cannabinoid CT-3 on chronic neuropathic pain: a randomized controlled trial. JAMA 2003;290: 1757-1762.

153. Salim K, Schneider U, Burstein S, Hoy L, Karst M. Pain measurements and side effect profile of the novel cannabinoid ajulemic acid. Neuropharmacology 2005;48:1164-1171.

154. Liu J, Li H, Burstein SH, Zurier RB, Chen JD. Activation and binding of peroxisome proliferator-activated receptor gamma by synthetic cannabinoid ajulemic acid. Mol Pharmacol 2003;63: 983-992.

155. Wilsey B, Marcotte T, Tsodikov A, et al. A randomized, placebocontrolled, crossover trial of cannabis cigarettes in neuropathic pain. J Pain 2008;9:506-521.

156. Notcutt W, Price M, Miller R, et al. Initial experiences with medicinal extracts of cannabis for chronic pain: results from 34 'N of 1' studies. Anaesthesia 2004;59:440-452.

157. Walker JM, Farney RJ, Rhondeau SM, et al. Chronic opioid use is a risk factor for the development of central sleep apnea and ataxic breathing. J Clin Sleep Med 2007;3:455-461.

158. Dimsdale JE, Norman D, DeJardin D, Wallace MS. The effect of opioids on sleep architecture. J Clin Sleep Med 2007;3:33-36.

159. Wade DT, Robson P, House H, Makela P, Aram J. A preliminary controlled study to determine whether whole-plant cannabis extracts can improve intractable neurogenic symptoms. Clin Rehabil 2003;17:21-29.

160. Wissel J, Haydn T, Muller J, et al. Low dose treatment with the synthetic cannabinoid Nabilone significantly reduces spasticityrelated pain: a double-blind placebo-controlled cross-over trial. J Neurol 2006;253:1337-1341.

161. Berlach DM, Shir Y, Ware MA. Experience with the synthetic cannabinoid nabilone in chronic noncancer pain. Pain Med 2006; 7:25-29.

162. Maurer M, Henn V, Dittrich A, Hofmann A. Delta-9-tetrahydrocannabinol shows antispastic and analgesic effects in a single case 
double-blind trial. Eur Arch Psychiatry Clin Neurosci 1990;240:1-4.

163. Hagenbach U, Luz S, Ghafoor N, et al. The treatment of spasticity with Delta9-tetrahydrocannabinol in persons with spinal cord injury. Spinal Cord 2007;45:551-562.

164. Attal N, Brasseur L, Guirimand D, Clermond-Gnamien S, Atlami S, Bouhassira D. Are oral cannabinoids safe and effective in refractory neuropathic pain? Eur J Pain 2004;8:173-177.

165. Clermont-Gnamien S, Atlani S, Attal N, Le Mercier F, Guirimand F, Brasseur L. [The therapeutic use of D9-tetrahydrocannabinol (dronabinol) in refractory neuropathic pain]. Presse Med 2002; 31:1840-1845.

166. Frank B, Serpell MG, Hughes J, Matthews JN, Kapur D. Comparison of analgesic effects and patient tolerability of nabilone and dihydrocodeine for chronic neuropathic pain: randomised, crossover, double blind study. Bmj 2008;336:199-201.

167. Pinsger M, Schimetta W, Volc D, Hiermann E, Riederer F, Polz W. [Benefits of an add-on treatment with the synthetic cannabinomimetic nabilone on patients with chronic pain - a randomized controlled trial]. Wien Klin Wochenschr 2006;118:327-335.

168. Narang S, Gibson D, Wasan AD, et al. Efficacy of dronabinol as an adjuvant treatment for chronic pain patients on opioid therapy. J Pain 2008;9:254-264.

169. Toth C, Au S. A prospective identification of neuropathic pain in specific chronic polyneuropathy syndromes and response to pharmacological therapy. Pain 2008;138:657-666.

170. Wang T, Collet JP, Shapiro S, Ware MA. Adverse effects of medical cannabinoids: a systematic review. CMAJ 2008;178: 1669-1678.

171. De Vry J, Kuhl E, Franken-Kunkel P, Eckel G. Pharmacological characterization of the chronic constriction injury model of neuropathic pain. Eur J Pharmacol 2004;491:137-148.

172. Pedersen LH, Blackburn-Munro G. Pharmacological characterisation of place escape/avoidance behaviour in the rat chronic constriction injury model of neuropathic pain. Psychopharmacology (Berl) 2006;185:208-217.

173. Hama AT, Urban MO. Antihyperalgesic effect of the cannabinoid agonist WIN55,212-2 is mediated through an interaction with spinal metabotropic glutamate-5 receptors in rats. Neurosci Lett 2004;358:21-24.

174. Yao BB, Hsieh GC, Frost JM, et al. In vitro and in vivo characterization of A-796260: a selective cannabinoid CB2 receptor agonist exhibiting analgesic activity in rodent pain models. Br J Pharmacol 2008;153:390-401.

175. Mitchell VA, Aslan S, Safaei R, Vaughan CW. Effect of the cannabinoid ajulemic acid on rat models of neuropathic and inflammatory pain. Neurosci Lett 2005;382:231-235.

176. Guindon J, Desroches J, Dani M, Beaulieu P. Pre-emptive antinociceptive effects of a synthetic cannabinoid in a model of neuropathic pain. Eur J Pharmacol 2007;568:173-176.

177. Valenzano KJ, Tafesse L, Lee G, et al. Pharmacological and pharmacokinetic characterization of the cannabinoid receptor 2 agonist, GW405833, utilizing rodent models of acute and chronic pain, anxiety, ataxia and catalepsy. Neuropharmacology 2005;48: $658-672$.

178. Whiteside GT, Gottshall SL, Boulet JM, et al. A role for cannabinoid receptors, but not endogenous opioids, in the antinociceptive activity of the CB2-selective agonist, GW405833. Eur J Pharmacol 2005;528:65-72.

179. Scott DA, Wright CE, Angus JA. Evidence that CB-1 and CB-2 cannabinoid receptors mediate antinociception in neuropathic pain in the rat. Pain 2004;109:124-131.

180. Worm K, Zhou QJ, Saeui CT, et al. Sulfamoyl benzamides as novel CB2 cannabinoid receptor ligands. Bioorg Med Chem Lett 2008; 18:2830-2835.

181. Diaz P, Xu J, Astruc-Diaz F, Pan HM, Brown DL, Naguib M. Design and synthesis of a novel series of N-alkyl isatin acylhydrazone derivatives that act as selective cannabinoid receptor 2 agonists for the treatment of neuropathic pain. J Med Chem 2008;51:4932-4947.

182. Dogrul A, Gul H, Yildiz O, Bilgin F, Guzeldemir ME. Cannabinoids blocks tactile allodynia in diabetic mice without attenuation of its antinociceptive effect. Neurosci Lett 2004; 368:82-86.

183. Ulugol A, Karadag HC, Ipci Y, Tamer M, Dokmeci I. The effect of WIN 55,212-2, a cannabinoid agonist, on tactile allodynia in diabetic rats. Neurosci Lett 2004;371:167-170. 